\title{
BAYESIAN REFINEMENT OF A STRATIFIED SEQUENCE OF RADIOMETRIC DATES FROM PUNTA DE CHIMINO, GUATEMALA
}

\section{Bruce R Bachand}

New World Archaeological Foundation, Department of Anthropology, Brigham Young University, 800 SWKT, Provo, Utah 84602, USA. Email: bruce_bachand@byu.edu.

ABSTRACT. Bayesian analysis of 6 radiocarbon and 2 luminescence determinations from Punta de Chimino's acropolis provides subcentury chronometric accuracy for a Protoclassic hiatus and a more decisive, incipient Early Classic abandonment. For the latter event, sensitivity tests and a redundant modal value pattern reduce the period of historical interest from a few centuries to several decades. The findings aid in selecting between 2 historical scenarios and demonstrate that improved chronological accuracy is attainable for sites and contexts lacking calendrical dates.

\section{INTRODUCTION}

Five years ago, the Mesoamerican archaeologist Joyce Marcus (2003:109) called on Mayanists to "refine traditional archaeological techniques to bring periods like the Preclassic and Protoclassic into sharper focus." She insisted that "we must figure out how to derive finer chronologies for periods with no dated monuments and from sites that lack dated monuments." The present paper is a response to that call, presenting results of a Bayesian study of radiometric determinations from the Lowland Maya center of Punta de Chimino, Guatemala (Figure 1).

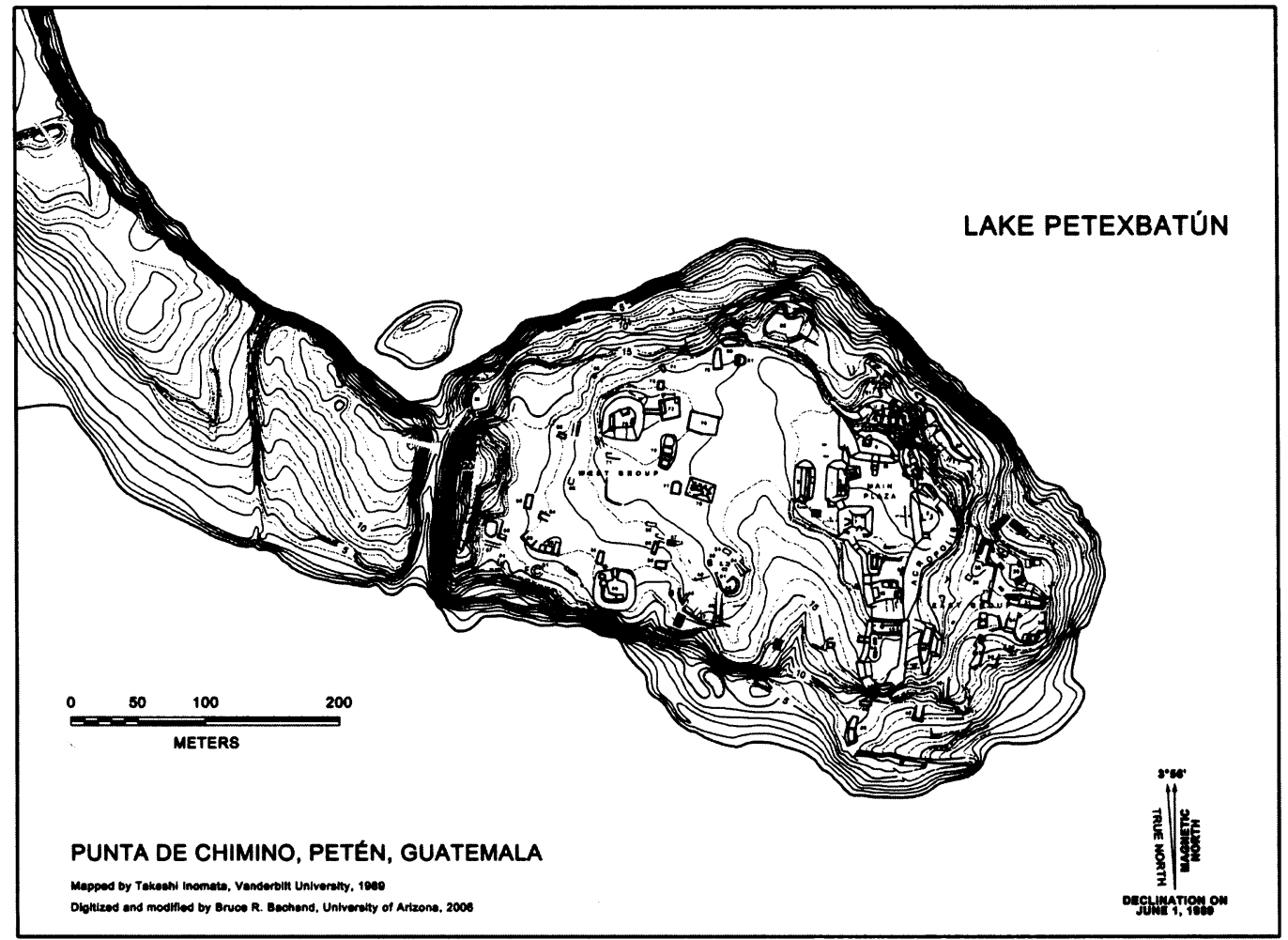

Figure 1 Site map 
Punta de Chimino's determinations address lasting uncertainties about the appearance, duration, and continuity of Protoclassic and Early Classic cultural phenomena in the Petexbatún region of Guatemala's southern Petén forest. Until now, no firm chronological placement has been proposed for the surmised Terminal Preclassic or Protoclassic population decrease around Lake Petexbatún (Foias 1996; Dunning et al. 1997). Equally uncertain has been the origin, duration, and continuity of subsequent Early Classic occupations in the region. Proper understanding of these events has been hindered by ceramic continuity and an absence of accurate chronometric readings and calendar dates. The Bayesian models presented in this paper suggest that the Protoclassic hiatus observed archaeologically at Punta de Chimino occurred between cal AD 170 and 200. After it was revitalized, the monumental center was used for another 1 or 2 centuries before it was ritually destroyed sometime between cal AD 420 and 450. This last event represents a punctuated halt within what is often considered a continuous, yet poorly documented, occupational period in the region. These findings provide negative evidence that Preclassic cultural lifeways continued into the Early Classic period in the Petexbatún.

Bayesian analysis of the Early Classic destruction was not a simple affair. Three accelerator mass spectrometry (AMS) determinations from well-controlled, closely contemporaneous archaeological contexts provided a calibrated, unsimulated calendar range of AD 350 to 600 for the abandonment. Bayesian simulated results consistently placed this event in the 5th century AD. Epigraphy and settlement data suggested that the cultural landscape was vastly different at both ends of this century. Importantly, the Bayesian modal values of the 3 simulated determinations all peaked near cal AD 430-450. This observation, along with other sensitivity tests and the majority of archaeological observations, led me to conclude that Punta de Chimino was most likely destroyed in the first half of the 5th century. Nevertheless, Bayesian results still left open the possibility that these dated events were not all contemporaneous, implying that the abandonment may have occurred in stages over several decades or half a century.

\section{BAYESIAN RADIOMETRY}

The 3 major scientific revolutions in radiocarbon dating - the method's initial creation and application, development of the calibration curve, and the advent of AMS dating-have resulted from innovations in the chemical and physical sciences. These revolutions highlight the reality that ${ }^{14} \mathrm{C}$ determinations are based on scientific laws, principles, and procedures that are entirely independent of archaeological systematics (Dean 1978). But a fourth ${ }^{14} \mathrm{C}$ revolution is afoot, and unlike previous ones, this one focuses on post-laboratory reduction of ${ }^{14} \mathrm{C}$ error terms by incorporating prior knowledge of archaeological systematics in mathematically complex statistical models rooted in Bayesian probability theory (Buck et al. 1996; Whittle and Bayliss 2007:22). This innovation addresses a longstanding grievance in the archaeological community that ${ }^{14} \mathrm{C}$ dates are too erratic and imprecise to isolate past events with the historical specificity that archaeologists desire. Though independent of archaeological observations, ${ }^{14} \mathrm{C}$ determinations are far from "absolute" as they rarely provide subcentury resolution.

Bayesian modeling of archaeologically stratified sequences of radiometric dates, primarily ${ }^{14} \mathrm{C}$, has been implemented with considerable success in Europe, Oceania, and Asia for more than a decade (Buck et al. 1991, 1992, 1994, 1996; Bronk Ramsey 1995; Bayliss et al. 1997, 2006, 2007b; Steier and Rom 2000; Anderson et al. 2001; Lu et al. 2001). ${ }^{1}$ The utility of Bayesian models for ${ }^{14} \mathrm{C}$ anal-

'Two cases from South America had broader regional and historical aims and differed methodologically from the site-specific stratigraphic approach I reference here and undertake in this paper. On the Peruvian coast (Buck et al. 1996:245-52), a case study was aimed at determining phase boundaries and detecting ${ }^{14} \mathrm{C}$ outliers for the Chancay culture. The Ecuadorian example was directed toward determining multiple phase boundaries for dozens of sites across the Jama River Valley (Buck et al. 1996:226-32; Zeidler et al. 1998). 
ysis has been so convincingly demonstrated that the latest atmospheric and marine ${ }^{14} \mathrm{C}$ calibration curves used for calibrating ${ }^{14} \mathrm{C}$ determinations are Bayesian-adjusted curves (Buck and Blackwell 2004; Reimer et al. 2004).

Bayesian models enable us to assign degrees of belief to increments of time that are often much reduced from those reported by laboratories. Since the dawn of ${ }^{14} \mathrm{C}$, archaeologists have ordered, summarized, accepted, and rejected ${ }^{14} \mathrm{C}$ determinations with varying degrees of confidence. But final judgments have often been intuitive or based on statistical inferences that do not account for archaeological or ${ }^{14} \mathrm{C}$ realities. With modern computing power, archaeological knowledge can be quantified and factored directly into simulations that help us determine where the true dates of radiometric determinations (often expressed as $\theta$ or theta) most likely lie.

The logic and mathematical details of the Bayesian approach to dating sequential archaeological events are presented in Bronk Ramsey $(1995,1998)$ and Buck et al. (1991, 1992, 1994, 1996:21826). All caveats and pitfalls outlined by Caitlin Buck in BCal's online introduction, by Christopher Bronk Ramsey in the OxCal v 3.10 user manual, and in various papers (Bronk Ramsey 2000; Steier and Rom 2000; Bayliss et al. 2007a) apply to the present investigation. Barring data entry errors, the accuracy of Bayesian results hinges on the accuracy of prior archaeological information placed into the model, thus the maxim, "garbage in, garbage out." Dated materials should closely correspond in time with the events they are intended to date and the stratigraphic order of these events should be well understood. A scenario noted in the OxCal manual is instructive, "sample A in pit 1 may be older than sample B in pit 2 even if pit 2 is older than pit 1" (Bronk Ramsey 2005). Important, then, is detailed description of dated samples and their contexts, a task prerequisite to transparent presentation of the variables, assumptions, and steps involved in model creation. Without this information, independent evaluation is impossible. Thorough evaluations should address 3 elements: 1) the scientific dating measurements; 2) choices made in model creation; and 3) the statistical analysis itself (Bronk Ramsey 1998:467). The danger with Bayesian results, as with any archaeological interpretations, is that they can become heuristic pillars for subsequent archaeological knowledge before they are subjected to rigorous cross-examination.

The key product in Bayesian analyses is the highest posterior density region (HPD), or credible interval (Buck et al. 1996:152-60; Howson and Urbach 2006:244-5). Bayesian credible intervals differ from frequentist confidence intervals in that the former are calculated by a constrained, stepwise sampling of prior information expressed in values of belief from 0 to 1 (e.g. 0.85), while the latter are calculated randomly from fixed numerical values of 0 or 1 .

In the current study, the HPD is essentially that portion of a probability curve or histogram that expresses where we can have the greatest mathematical belief that a true date lies, given a determination's laboratory reading, atmospheric calibration, and determined stratigraphic position. When a histogram is unimodal or has 1 peak, we can determine the time interval within which a specific date lies with $95.4 \%$ a posteriori credibility or "believability." When multimodal, the highest, most probable segment of the curve will provide an a posteriori credible interval below $95.4 \%$, and a second credible interval will often be included as part of the posterior estimate.

A critical element in the present study is the modal value or MAP (maximum a posteriori). The modal value is the highest probability density or most likely date (often a year) in the HPD. Modal values can show how an HPD is skewed or subdivided and, when considered with other criteriathe overall shape of the HPD region and the shapes of other HPDs-they can be rather informative. Modal values can be misleading, however, without considering these other criteria. A Bayesian modal value is not a measure of central tendency. It is simply the value with the highest posterior 
probability among all other values contained in the HPD region, given prior assumptions. It is obtained visually from the HPD histogram and can be evaluated statistically with query operations provided in Bayesian computer software.

The following models were created and run on 2 independently designed Bayesian computer platforms, the University of Sheffield's BCal program (http://bcal.shef.ac.uk/) and the Bayesian module in the University of Oxford's OxCal v $3.10{ }^{14} \mathrm{C}$ calibration program (http://www.rlaha.ox.ac.uk/ oxcal/oxcal.htm). The 2 platforms employ Markov chain Monte Carlo (MCMC) iterative sampling for calculations, but differ in fundamental respects. For example, OxCal allows input of luminescence, dendro, and uranium series dates while $\mathrm{BCal}$ works with ${ }^{14} \mathrm{C}$ only. $\mathrm{BCal}$ allows users to assign a prior probability (in percentage form) to a specific determination if that determination is suspected to be an outlier before running it in the simulation. An advantage with OxCal, however, is that it provides agreement tests and multimodal probability percentages to help users evaluate results. Despite these differences, $\mathrm{BCal}$ and $\mathrm{OxCal}$ results were generally identical, unless an outlier probability was specified for a ${ }^{14} \mathrm{C}$ determination in $\mathrm{BCal}$.

The models presented in this paper were simulated 3 times before conclusions were drawn about results. As Buck, Christen, and James explain in BCal's online introduction, when the MCMC method is used, "no two runs of the code will produce the same answers." Nevertheless, "provided that the method is working well, you should find that multiple runs with different random seeds produce results which are very similar and certainly within the tolerance of the other errors inherent in ${ }^{14} \mathrm{C}$ dating." Models without luminescence dates were run on both $\mathrm{BCal}$ and $\mathrm{OxCal}$ to provide a crosscheck on results across simulation platforms. When a specific relationship was in doubt, I altered the parameter, reran the simulation, and compared results. Details of such "sensitivity analyses" are provided below. Unless otherwise noted, all results are averages from 3 Bayesian runs and correspond to the $95.4 \%$ highest posterior density (HPD) region.

\section{PUNTA DE CHIMINO}

Punta de Chimino's acropolis possesses a stratigraphic record of public activity spanning $1200 \mathrm{yr}$ from $700 \mathrm{cal}$ BC to cal AD 900. Excavations conducted by Vanderbilt University in the late 1980s and early 1990s (Demarest 2006) and by the University of Arizona in 2004 and 2005 (Bachand 2006) provide evidence of shifts in construction methods, monument design and use, as well as destruction, repair, ritual termination, abandonment, and re-occupation of the acropolis. Roughly two-thirds of the excavated acropolis volume pertains to pre-Classic eras antedating the 5th century AD. At least 2 abandonment episodes are discernible in the early half of the stratigraphic sequence: a brief interruption in the middle of the Protoclassic (about cal AD 175), and a more decisive abandonment during the Protoclassic-Early Classic transition (about cal AD 400/450). This latter abandonment was represented by ritual defacement of Structure 6A-Sub 3's elaborately adorned iconographic façade, removal of an adjacent stela, and a discontinued renovation atop Structure 7-Sub 3. Little was known about Protoclassic history in the Petexbatún region prior to the Arizona field research.

\section{Determinations}

Eleven AMS and 4 luminescence determinations were acquired from a stratified succession of burials, building surfaces, construction fills, and termination deposits in Mounds 6 and 7 (Figures 2, 3, and 4). The goal was to obtain a series of near "target event" determinations (Dean 1978) in closely staggered stratigraphic succession. This procedure increased the odds of obtaining assays with overlapping error terms, a highly desirable condition for conducting fine-grained Bayesian analysis of site 
stratigraphy and history. Twenty-two samples of charcoal, human bone, and pottery were collected in the field. Fifteen were selected for AMS and luminescence testing. Nine of 15 were associated stratigraphically with the middle and end of the Protoclassic era, which dates broadly from about $75 \mathrm{cal}$ BC to cal AD 420 (Brady et al. 1998). One result, a luminescence determination (UW-1324), was far too old for its context and was deemed unsuitable for Bayesian analysis. Laboratory results and archaeological assessments of the remaining 8 Protoclassic determinations were as follows.

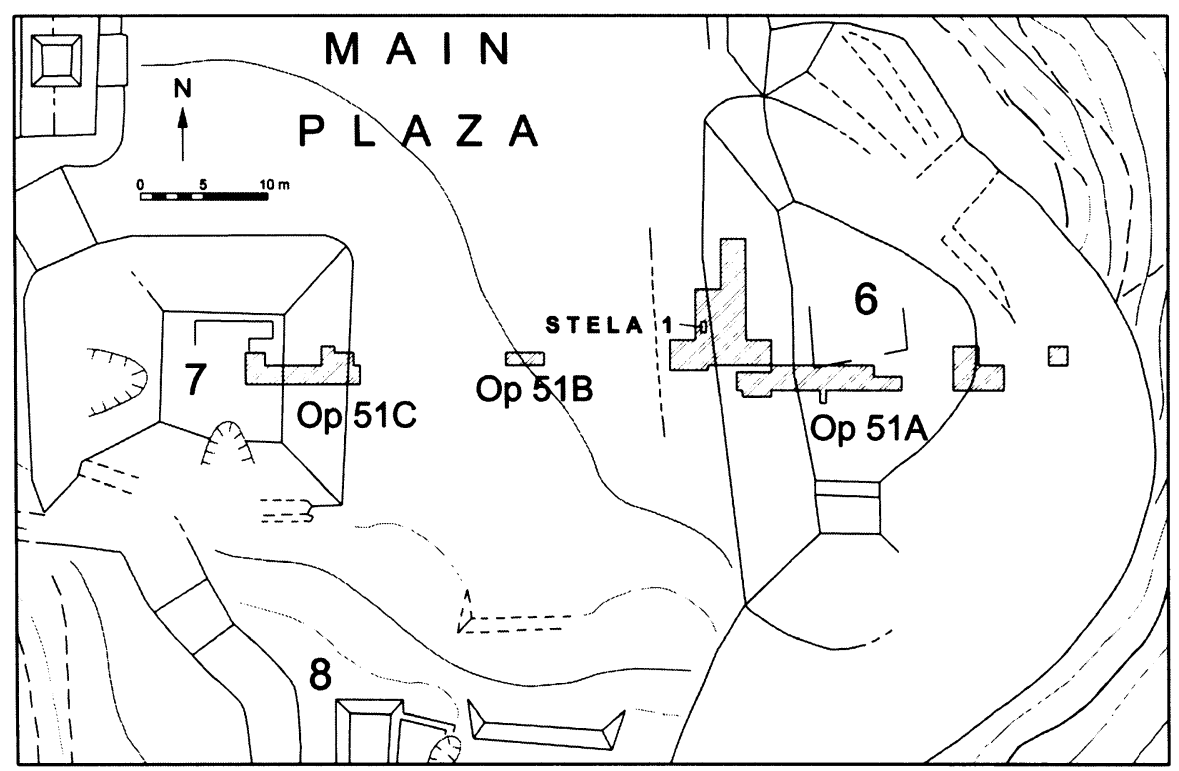

Figure 2 Acropolis map showing excavation locations

AA-66267

$1756 \pm 41$

$\delta^{13} \mathrm{C}=-9.8 \%$

A 4.0-g tibia fragment was sampled from Burial 104-a fully articulated skeleton of a $12 \pm 3$ yr-old adolescent discovered in the fill of Structure 6A-Sub 5 (Figure 3). The body was placed in a stonelined rectangular cist $20 \mathrm{~cm}$ below Sub 5's upper surface. According to the laboratory, there was sufficient bone collagen for dating following rootlet removal in pretreatment. Curiously, the dated event (occupant's death) postdated Structure 6A-Sub 5 construction-the latest ceramics found in the fill were Late Preclassic Chicanel. Stratigraphically, however, Burial 104 antedated Sub 4 construction. A dark soil matrix, missing frontal bones, and polychrome sherds around the skull indicated post-depositional cultural alteration prior to Sub 4 construction. The AMS result along with the burial's proximity to the Sub 5 surface suggested that the interment was intrusive into Sub 5, where it remained until it was disturbed by post-depositional removal of facials sometime prior to Sub 4 construction. Conclusion: Burial 104's occupant died sometime between the Sub 5 and Sub 4 construction episodes.

AA-66268

$1871 \pm 43$

$\delta^{13} \mathrm{C}=-10.0 \%$

A 2.0-g tibia fragment was sampled from Burial 102-an (articulated?) middle-aged adult male skeleton that was intrusive into the lower platform of Structure 6A-Sub 4 (Figure 3 ). ${ }^{2}$ The intrusive

${ }^{2}$ This figure plots Burial 102's location, but additional stratigraphic details are missing because this burial was located off the profile line. See Bachand (2006: Figure 35) for a precise illustration of Burial 102's provenience. 

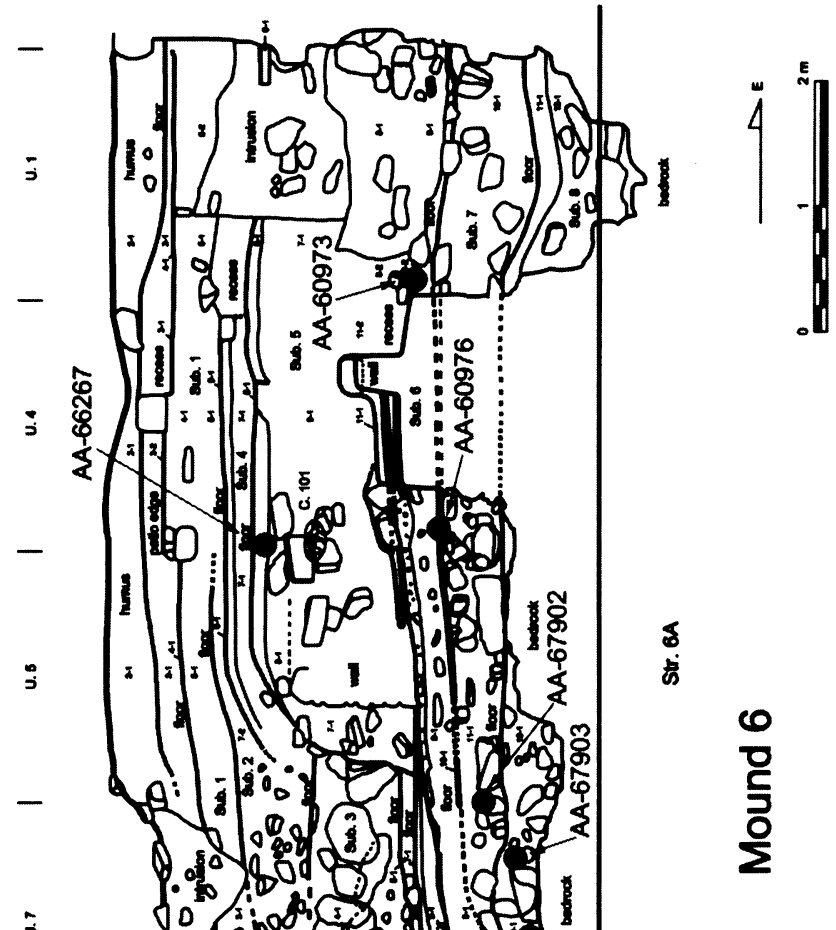

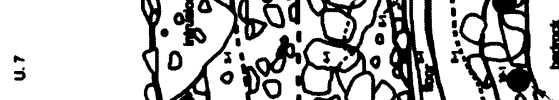
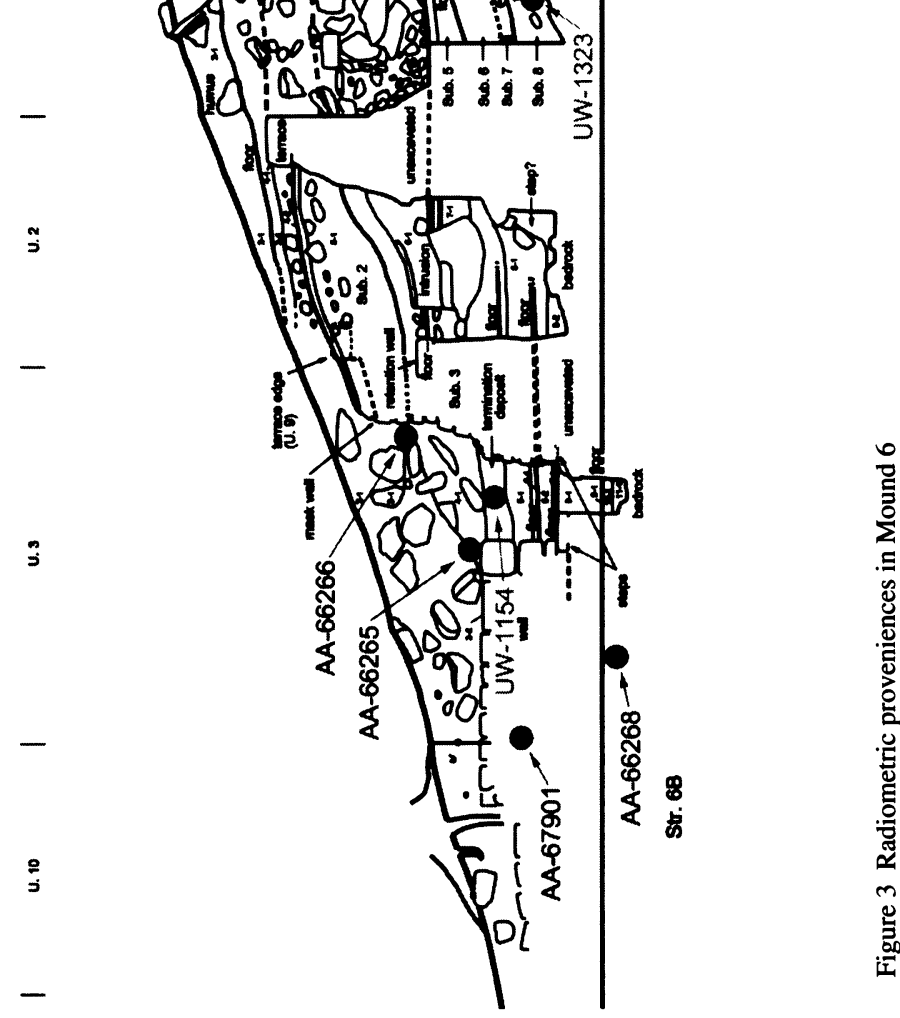


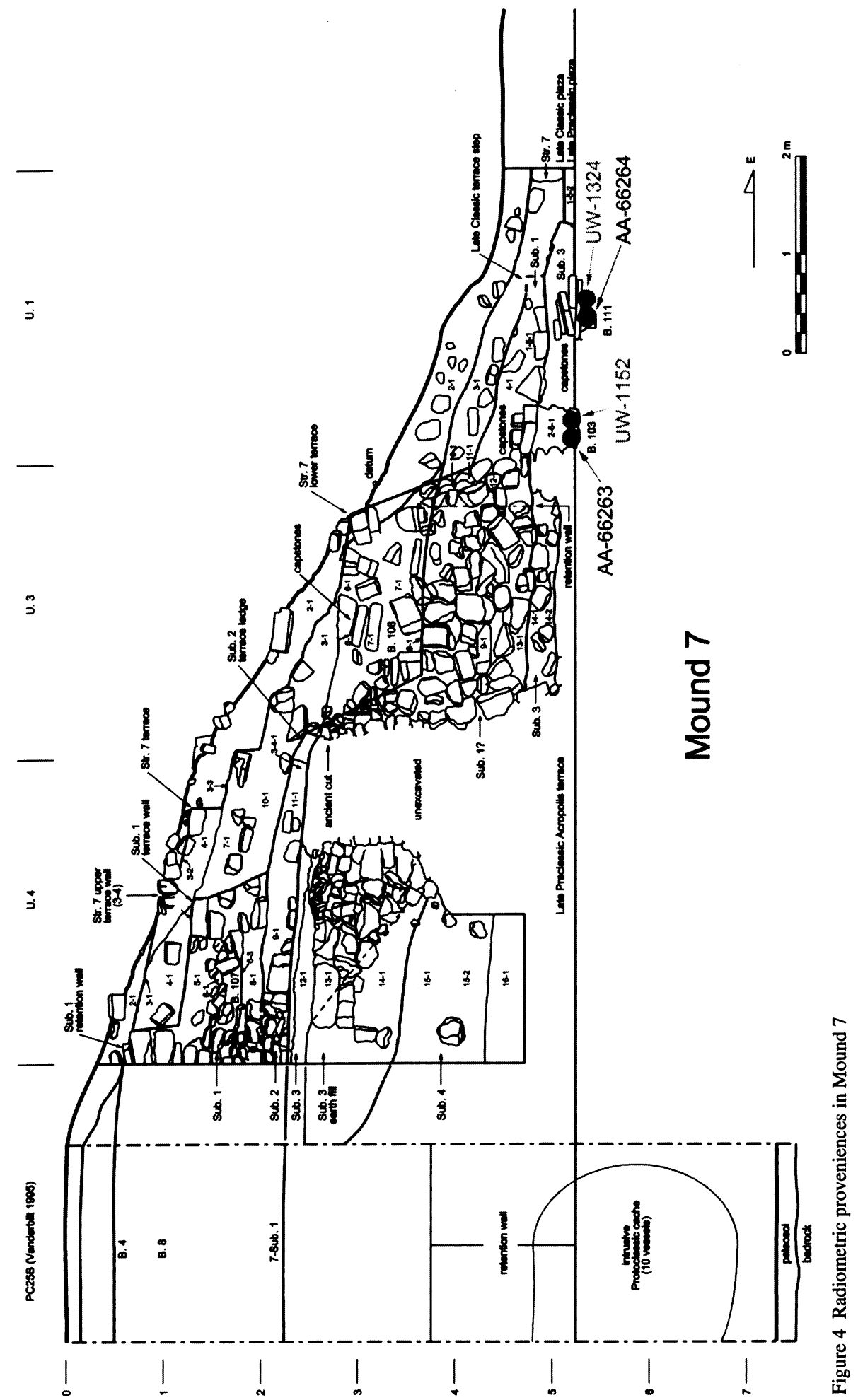


grave pit was capped by the south wall of Structure 6B, a stela enclosure. The latest pottery in Sub 4's fill was Early Protoclassic, and in Structure 6B fill it was Late Protoclassic. The dated event (occupant's death) postdated Sub 4 terrace construction and predated Structure 6B construction. Structural damage of monumental buildings on the Sub 4 time horizon suggested acropolis abandonment between Early and Late Protoclassic occupations. Because this skeleton was intrusive and most likely primary (i.e. not curated), the occupant's death was probably linked to the site's Late Protoclassic revitalization. Conclusion: Burial 102's occupant died sometime between the Structure 6ASub 4 and 6B construction episodes, but it was probably more closely associated with Structure 6B, a building for which this event may have been dedicatory.

AA-66264

$1568 \pm 45$

$\delta^{13} \mathrm{C}=-8.9 \%$ o

A 3.0-g femur segment was obtained from Burial 111-a semi-complete, articulated adult skeleton placed in a stone-lined and capped rectangular cist in the fill of Structure 7-Sub 3's basal platform (Figure 4). The latest ceramics in the Sub 3 fill and grave were Late Protoclassic in date. The interment was primary and dedicatory to Sub 3 construction, a building capped with an unfinished Early Classic renovation. Conclusion: Burial 111's occupant must have died during, or a short time before, Sub 3 construction. Only the early range of this assay overlapped with archaeological projections.

AA-66263

$1634 \pm 53$

$\delta^{13} \mathrm{C}=-10.5 \%$ o

A 5.0-g femur fragment was tested from Burial 103-the badly deteriorated skeleton of an adult (male?) sealed in an intrusive stone-lined cylindrical cavity at the base of Structure 7-Sub 3 (Figure 4). Fortunately, there was enough skeletal articulation, superposition, and preservation to describe Burial 103 as a primary, seated burial not disturbed by later inhabitants. The grave penetrated Sub 3's basal platform and was capped with thick stone slabs. A slightly low C:N ratio ( 1\% below usual lab cutoff) was registered prior to running the bone sample. ${ }^{3}$ The effect seems to have been negligible, as the result conformed to archaeological expectations. All 3 grave vessels were incipient Early Classic in style. Conclusion: Burial 103's occupant died after Sub 3 construction around the onset of the Early Classic period.

\section{AA-67901}

$1582 \pm 37$

$\delta^{13} \mathrm{C}=-\mathbf{2 6 . 3 \%}$

A single specimen of carbonized mature wood (Burseraceae family, Protium sp., especially $P$. copal [copal, incienso] or Bursera sp. [gum elimi, gumbo limbo]) weighing $4.0 \mathrm{~g}$ was extracted from a dark soil stain on the floor against the south side of an in situ stela butt (Figure 3). Ceramics on the floor were Late Protoclassic in date, but originated from the surrounding Structure 6B wall fall. Lithics with thermal markings, pyrite plaque pieces, urn fragments, and charcoal specks on the floor suggested ritual use of fire. The current specimen was possibly an aromatic sapwood extracted from the secretory portion of a hardwood tree, i.e. between the inner heartwood and bark. Its cell structure was linear, implying that it was splintered mature wood, not roundwood, such as fine branch or "twig" terminal growth. The tree from which this specimen derived was probably cut or felled around the time of Stela 1's destruction. Inbuilt age or "old wood" does not appear to be a distorting factor since the calibrated ${ }^{14} \mathrm{C}$ result is not recognizably older than the stratigraphic context. Conclusion: The resinous wood was most likely extracted from the outer (younger) rings of a tree immediately prior to its use in a fire ritual accompanying the removal of Stela 1.

\footnotetext{
${ }^{3}$ The $\mathrm{C}: \mathrm{N}$ ratio measures the proportion of carbon to nitrogen in a bone sample. This ratio provides a rough estimate of a bone's chemical integrity after it undergoes pretreatment and purification in the laboratory.
} 
A 2.0-g femur fragment was sampled from Burial 106-the disarticulated skeletal remains of a juvenile (1-2 yr of age) found in the upper portion of a refuse deposit that covered the rear ledge of Structure 6B, the Stela 1 enclosure (Figure 3). The bones were tightly clustered, but it remains unclear whether the interment was primary or secondary. No taphonomic markings were observed. The bones were hard, glossy, and yellowish in hue and exhibited no signs of sun bleaching. The individual either died prior to or concurrent with the refuse deposition episode. This refuse deposit provides a terminus ante quem for the use of the Structure 6A-Sub 3 mask wall and the adjacent Structure 6B stela enclosure, and appears to signal acropolis abandonment. The latest ceramics in the refuse deposit are Early Classic (Tzakol 2) in date. Conclusion: This child probably died close to the time of ritual termination because 1) the bone preservation is exceptional, suggesting the corpse decomposed within the refuse; 2 ) the first $70 \mathrm{yr}$ of the assay's calibrated range are too early for the context; and 3 ) the bones were covered by the Early Classic refuse deposit, which was capped by a Late Classic construction dated by ${ }^{14} \mathrm{C}$ and ceramics to the 7th or 8th century AD (Bachand 2006:412).

UW-1152

$180 \mathrm{BC} \pm 520$

TL $(8.21 \pm 1.85)$

An unnamed orange polychrome vase was dated from Burial 103 in Structure 7-Sub 3 (Figure 4). The vase was 1 of 3 incipient Early Classic vessels discovered in Burial 103, a stone-paved cylindrical cist. The event of interest is the vessel's manufacture prior to placement in Burial 103. The dosage plateau region of $250-300^{\circ} \mathrm{C}$ and the anomalously high OSL (optically stimulated luminescence) equivalent dose value suggest that the OSL signal was insufficiently reset at the time of vessel manufacture, a phenomenon normally attributed to low firing temperature. However, Maya polychromes are generally believed to have been fired at temperatures exceeding 700 or $800{ }^{\circ} \mathrm{C}$. The weak signal may therefore result from an absence of quartz and the presence of feldspars, which exhibit poor luminescence, or mica, whose luminescence qualities remain poorly understood (James Feathers, personal communication, 2006). A more reliable thermoluminescence (TL) dose rate of $8.21 \pm 1.85$ was determined via additive dose extrapolation, an operation that produced a TL date with a high error term. Conclusion: Only the TL result's upper terminus (AD 340) approaches the expected manufacture date of the vessel (cal AD 300-400).

\section{UW-1154}

$44 \mathrm{BC} \pm 410$

OSL (4.25 \pm 0.38$)$

The dated object was a Dos Arroyos Orange polychrome sherd sampled from a partial vessel discovered at the base of mask armature 1 in the large Early Classic refuse deposit between Structures $6 \mathrm{~A}$ and $6 \mathrm{~B}$ (Figure 3). The dated event is the vessel's manufacture prior to discard in a midden from which the deposit's contents are believed to derive. The OSL result was $44 \mathrm{BC} \pm 410$ (fading was not a factor). The TL result produced a late Pleistocene age. One or 2 sherds in this deposit are possibly Tzakol 3 in date; the others are Tzakol 2 . A dosage plateau region of $260-300{ }^{\circ} \mathrm{C}$ implied a low firing temperature, but again, different luminescence properties of various materials may be a factor. The equivalent OSL dose rate $(4.25 \pm 0.38)$ was reasonable, but failure to recover the known dose via a dose recovery test and the assay's low chronological resolution call into question the date's reliability. Conclusion: Only the upper boundary of the OSL result (AD 366) lies within the commonly believed start date of Dos Arroyos Orange Polychrome pottery production between cal AD 300-400 (Smith and Gifford 1966:154, 157; Sabloff 1975). 


\section{Prior Assumptions}

Additional inferences are needed to arrange each determination in a temporal sequence. In doing so, one gains an appreciation for the varied choices, premises, and logical nesting that occur in scientific analysis. The advantage of the Bayesian approach is that prior assumptions are made explicit, which makes results more transparent for independent review. The 8 determinations above were arranged sequentially, as shown in Figures 5 and 6, and based on the following prior assumptions:

- Burial 104 (AA-66267) stratigraphically precedes Burial 102 (AA-66268). Prior assumption: The death dates of the occupants in B. 104 and B. 102 seem to closely correspond in time with their archaeological contexts. The occupant of B. 104 therefore died before the occupant of B. 102 (a viable, but not fail-safe, assumption). This placement assumes no recent contamination of the B. 104 AMS sample, and that B. 102 is not secondary in nature.

- Burial 102 (AA-66268) stratigraphically precedes the construction of the Structure 6B stela enclosure (Late Protoclassic), and is intrusive into the Structure 6A-Sub 4 (Early Protoclassic) terrace. B. 102 is therefore most likely Late Protoclassic in date. What, then, is the temporal relationship between B. 102 and another Late Protoclassic interment across the plaza, Burial 111? Ancient construction techniques and ${ }^{14} \mathrm{C}$ assays imply that the Structure $6 \mathrm{~B}$ stela enclosure predates construction of the Structure 6A-Sub 3 mask wall and Structure 7-Sub 3 by an unknown temporal margin, even though ceramics indicate that all 3 date to the Late Protoclassic period. B. 111 is most likely later than B. 102 because it: 1) is an integral component of the apparently later Structure 7-Sub 3 construction; 2) exhibits cultural traits commonly affiliated with the end of the Late Protoclassic (pyrite dental inlays, lotus-style body position, semi-waxy brown pottery); and 3) has a ${ }^{14} \mathrm{C}$ result that not only postdates, but fails to overlap with B. 102's. Prior assumption: B. 102's occupant died before B. 111's occupant (AA-66264).

- Burial 111 (AA-66264) stratigraphically precedes Burial 103 (AA-66263). Prior assumptions: B. 111's occupant died prior to B. 103's occupant. The unnamed orange polychrome vase in B. 103 (UW-1152) was probably made before the death of B. 103's occupant since there is no sign of grave re-entry. This vessel could have been made before B. 111's occupant died, although its style and context jointly imply a manufacture date between the 2 mortality events. The prior assumption that this vessel was made between the 2 deaths is untestable due to the broad, uniform (i.e. non-normal, non-Gaussian) distribution of its luminescence time range. ${ }^{4}$

- Burial 111 (AA-66264) precedes the destruction of Stela 1 and its enclosure Structure 6B on stratigraphic and ceramic grounds. A possibility exists that Stela 1 and Structure 6B were destroyed a short time before the termination of the Structure 6A-Sub 3 mask wall, but this is far from certain. Burial 103 (AA-66263) could be prior to or coeval with these 2 destruction contexts, between the first 2 and third, or coeval with the third. What is certain is that B. 111 stratigraphically and ceramically predates the destruction of Stela 1, Structure 6B, and the Structure 6A-Sub 3 (mask wall), as well as B. 103. However, the precise chronological sequence among B. 103 and the 2 destruction contexts mentioned above remains unclear. Prior assumptions: B. 111 predates the death of the botanical material (AA-67901) used in the ritual at the base of Stela 1 . Contemporaneity is assumed among the tree component's death, its burning and placement near Stela 1, and the monument's removal. No order can be assumed among the Stela 1 botanical material, B. 103, and B. 106, as these determinations are too closely related in time to be seriated archaeologically.

\footnotetext{
${ }^{4}$ Nothing about a luminescence time range indicates that any point within that range is more likely to be the true age than any other. Thus, the Gaussian shape of a pre-simulated TL histogram in OxCal is somewhat misleading (see e.g. Figure 4).
} 
- Ceramic stratigraphy suggests that the Dos Arroyos Orange Polychrome dish in the mask wall termination deposit was made (UW-1154) after Burial 111 and before Burial 106, assuming B. 106 is not secondary. Prior assumption: The Dos Arroyos Orange Polychrome vessel was made sometime after the death of B. 111's occupant and before the death of the juvenile labeled as B. 106.

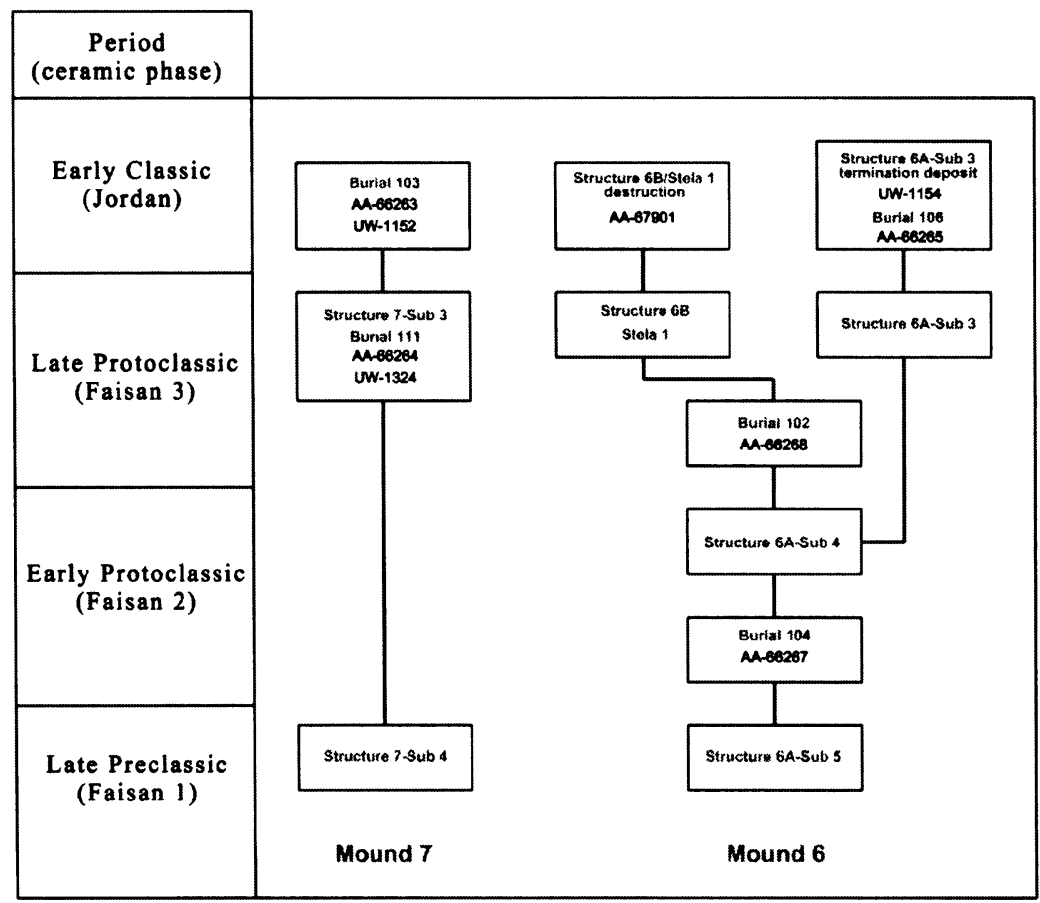

Figure 5 Summary of prior stratigraphic information

$\theta_{\text {B. } 104 \text { death }}>\theta_{\text {B. } 102 \text { death }}>\theta_{\text {B. } 111 \text { death }}>\theta_{\text {B. } 103 \text { poly vase manufacture }}>\theta_{\text {B. } 103 \text { death }}$

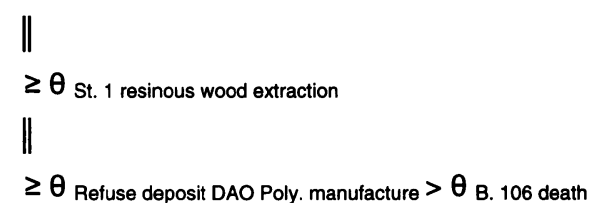

Early Protoclassic $\rightarrow$

Faisan 2
Late Protoclassic $\rightarrow$ Faisan 3
Early Classic $\rightarrow$ Jordan

key:

$\theta \quad$ theta (true calendar date of the dated event)

$>\quad$ after previous dated event

$\geq \quad$ after or around same time as previous dated event

\| possible contemporaneous dated event

Figure 6 Formal expression of the sequential order proposed for the acropolis determinations. Subscripts provide the context and dated event. Ceramic phases are italicized. 
The above prior assumptions are summarized in Table 1 and illustrated schematically in Figures 5 and 6. These prior assumptions helped me isolate the true timing of Punta de Chimino's events with a chronological exactness that is unattainable using unsimulated determinations with or without the aid of frequentist statistical methods such as $\chi^{2}$ tests, Student's $t$ distribution, ANOVA, assay averaging, and non-Bayesian simulation. Bowman (1990:60-2) provides a succinct explanation of why this is so, and Shott (1992) is illustrative of the statistical dilemmas described by Bowman. The 5 Bayesian models that follow are constrained by my prior archaeological assumptions and, given this current knowledge, are believed to present a more accurate reading of the timing and span of the Protoclassic hiatus, Early Classic abandonment, and existence of Stela 1 at Punta de Chimino. Model definitions are presented in their entirety in the Appendix (pages 44-51).

Table 1 Summary of prior archaeological assumptions.

\begin{tabular}{|c|c|}
\hline Prior assumption & Symbolized \\
\hline Burial 104 occupant died prior to Burial 102 occupant & B. $104<$ B. 102 \\
\hline $\begin{array}{l}\text { Burial } 102 \text { predates Str. 6B stela enclosure and Str. 7- } \\
\text { Sub 3, which contains Burial } 111\end{array}$ & B. $102<$ B. 111 \\
\hline Burial 111's occupant died prior to Burial 103's occupant & B. $111<$ B. 103 \\
\hline $\begin{array}{l}\text { Burial 103's unnamed orange poly. vessel was made } \\
\text { before Burial 103's occupant died and likely postdates } \\
\text { the death of Burial 111's occupant }\end{array}$ & B. $111<$ unnamed orange poly. < B. 103 \\
\hline $\begin{array}{l}\text { Burial } 111 \text { predates destruction of Str. 6B stela enclosure } \\
\text { and Stela } 1 \text { (resinous wood) }\end{array}$ & B. $111<$ resinous wood \\
\hline $\begin{array}{l}\text { Burial } 103 \text { occupant death, Str. 6B and Stela } 1 \text { destruction } \\
\text { (resinous wood), and Burial } 106 \text { occupant death are } \\
\text { archaeologically contemporaneous }\end{array}$ & B. $103=$ resinous wood $=$ B. 106 \\
\hline $\begin{array}{l}\text { Dos Arroyos vessel was made after Burial } 111 \text { occupant } \\
\text { died and before Burial } 106 \text { occupant died }\end{array}$ & B. $111<$ DO vessel < B. 106 \\
\hline
\end{tabular}

\section{Model 1: The Protoclassic to Early Classic Acropolis Event Sequence}

The calendar dates represented by radiometric determinations $\theta_{1}$ through $\theta_{8}$ (Table 2) were modeled in OxCal v 3.10, a program capable of simulating luminescence determinations. No order was assumed among the 4 latest determinations; these were entered as "unordered" Early Classic events in the model definition. The model was run 3 times with a Markov chain Monte Carlo (MCMC) sampler that ended at 56,995, 114,295, and 28,496 iterations, respectively. Each time, the simulation corrected 2 instances of inverted dates and calculated the most likely chronological order for the 4 unordered Early Classic events. Bayesian results are presented in Tables 1 and 2 and Figures 7 and 8.

All 8 determinations fell within a 300-yr timespan from cal AD 150 to 500 (Figure 7). Noteworthy was invariable placement of Burial 103 (AA-66263) at the start of the unordered Early Classic sequence. More will be said about this important interment below. The current model allows us to see the entire Protoclassic to Early Classic event sequence at a glance.

Figure 8 illustrates the inherent "looseness" of unsimulated radiometric results. The graph to the left illustrates how the median date line is wiggly and erratic even in a relatively stable section of the ${ }^{14} \mathrm{C}$ calibration curve. This graph demonstrates that a sequence of carefully selected, high-quality determinations may provide little beyond what archaeologists can guess on their own with an understanding of regional artifact sequences and local stratigraphy. The graph to the right, however, accounts for prior archaeological knowledge and site stratigraphy. It corrects much of the "noise" in the left graph and allows finer historical judgments to be made with greater confidence. 
Table 2 Simulated Bayesian order and HPD (highest posterior density) probabilities for each determination in Model 1.

\begin{tabular}{|c|c|c|c|c|c|c|}
\hline $\begin{array}{l}\text { Calendar } \\
\text { date }\end{array}$ & Lab nr & Context & Dated material & Determination & $2-\sigma$ calibration & Bayesian HPD \\
\hline 1 & AA- 66267 & B. 104 & tibia & $1756 \pm 41$ & AD 139-389 & AD 133-323 (95.4\%) \\
\hline 2 & AA- 66268 & B. 102 & tibia & $1871 \pm 43$ & AD 53-241 & $\begin{array}{l}\text { AD 151-261 (51.3\%), } \\
\text { AD 278-344 (44\%) }\end{array}$ \\
\hline 3 & AA-66264 & B. 111 & femur & $1568 \pm 45$ & AD 406-594 & $\begin{array}{l}\text { AD 260-280 }(5.4 \%) \text {, } \\
\text { AD 325-473 (90\%) }\end{array}$ \\
\hline 4 & UW-1152 & B. 103 & poly. vase & $\begin{array}{l}180 \mathrm{BC} \pm 520 \\
(\mathrm{TL})\end{array}$ & $\mathrm{n} / \mathrm{a}$ & AD 328-504 (95.4\%) \\
\hline 5 & AA- 66263 & B. 103 & femur & $1634 \pm 53$ & AD 258-545 & AD $378-550(95.4 \%)$ \\
\hline 6 & AA-67901 & Stela 1 & resinous wood & $1582 \pm 37$ & $\mathrm{AD} 406-562$ & AD 412-551 (95.4\%) \\
\hline 7 & UW-1154 & $\begin{array}{l}\text { Md. } 6 \\
\text { midden }\end{array}$ & $\begin{array}{l}\text { DAO poly. } \\
\text { sherd }\end{array}$ & $\begin{array}{l}44 \mathrm{BC} \pm 410 \\
(\mathrm{OSL})\end{array}$ & $\mathrm{n} / \mathrm{a}$ & AD $351-634(95.4 \%)$ \\
\hline 8 & AA- 66265 & B. 106 & femur & $1613 \pm 45$ & AD 339-553 & AD 392-546 (95.4\%) \\
\hline
\end{tabular}

Atmospheric data from Reimer et al (2004);OxCal v3.10 Bronk Ramsey (2005); cub r:5 sd:2 prob usp[chron]

Sequence Proto-EC Acropolis Sequence $\left\{A=36.8 \%\left(A^{\prime} c=60.0 \%\right)\right\}$

Boundary start

$A A-66267 \quad 78.7 \%$

$A A-66268 \quad 42.6 \%$

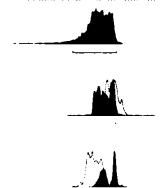

$A A-66264 \quad 45.8 \%$

L_Date UW-1152 $64.3 \%$

Order Early Classic events

$A A-66263 \quad 103.4 \%$

$A A-67901 \quad 103.9 \%$

L_Date UW-1154 51.4\%

$A A-66265108.4 \%$

Boundary end

6000BC5000BC4000BC3000BC2000BC1000BC BC/AD 1000AD2000AD3000AD

\section{Calendar date}

Figure 7 Model 1 Bayesian result graphed in OxCal v 3.10 (Bronk Ramsey 2005). Dark histograms are posterior distributions when prior archaeological knowledge is accounted for. Outlined histograms are calibrated AMS probabilities and luminescence ranges before Bayesian simulation. Percentages at top of plot indicate overall model agreement (in this case " $\mathrm{A}$ " falls below $60 \%$, suggesting the model might be worth re-evaluating). Individual percentages indicate degree of agreement between prior and posterior distributions. Those over $100 \%$ indicate agreement only in the original distribution's peak. 


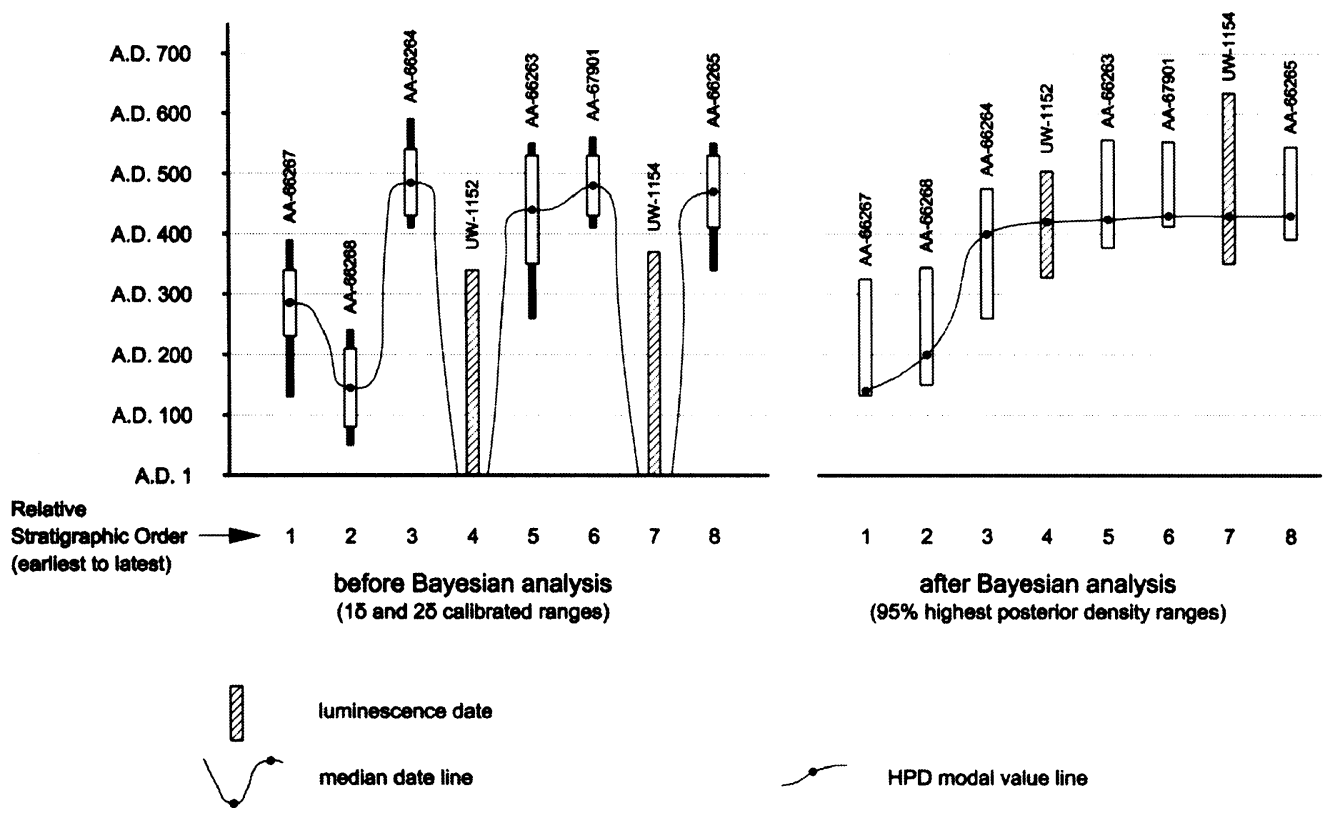

Figure 8 Alternative method of illustrating the effect of Bayesian simulation on the Model 1 determinations (order of last 4 determinations determined by the simulation). Two ${ }^{14} \mathrm{C}$ inversions are corrected and luminescence dates fall into more acceptable ranges.

\section{Sensitivity Tests}

Models 2 through 5 subdivide the main model and essentially test the "pull" of specific determinations on others. Minor adjustments or refinements to the main model were made when warranted. These simulations were undertaken in 2006 in OxCal v 3.10 and $\mathrm{BCal}$ and the results are presented in Table 3.

Table 3 HPD modal values for each determination. Modal values for each mode in a bimodal HPD are separated by a comma. Model number identified in parentheses. Inferred date is surmised from Bayesian analysis.

\begin{tabular}{llll}
\hline $\begin{array}{l}\text { Calendar } \\
\text { date }\end{array}$ & Dated event & HPD modal values & Inferred date \\
\hline 1 & B. 104 death & AD 180, 250 (1); AD 140 (2); AD 140 (4) & AD 140-180 \\
2 & B. 102 death & AD 200, 320 (1); AD 210 (2); AD 200, 310 (4) & AD 200-250 \\
3 & B. 111 death & AD 410 (1); AD 430 (3) & AD 300-400 \\
4 & $\begin{array}{l}\text { B. 103 poly. vase } \\
\text { manufacture }\end{array}$ & AD 420 (1) & AD 420 \\
5 & B. 103 death & AD 450 (1); AD 420, 530 (3); AD 420, 490 (5) & AD 420-430 \\
6 & St. 1 resinous wood death & AD 450 (1); AD 430 (4); AD 430 (5) & AD 430-450 \\
7 & DO vessel manufacture & AD 450 (1) & AD 420-450 \\
8 & B. 106 death & AD 450 (1) & AD 430-450 \\
\hline
\end{tabular}

In writing this paper, I decided to test whether inclusion of thermoluminescence dates significantly affected model results. This was done in OxCal $v$ 4.0.1. When the $2 \mathrm{TL}$ determinations were 
removed, overall model agreement improved from $36.8 \%$ to $60.4 \%,{ }^{5}$ Burial 111's HPD region became $60 \mathrm{yr}$ later, and the HPD regions for the 3 Early Classic ${ }^{14} \mathrm{C}$ determinations were $10-12 \mathrm{yr}$ later-disparities that encouraged further investigation.

With TL dates extracted, I could now run Model 1 in BCal. I configured the model in 2 ways. The first model, Model 1a, assumed a 100\% outlier probability for Burial 111 (an inverted determination) and included Burial 103 in the unordered group of Early Classic events postdating Burial 111. The second model, Model $1 \mathrm{~b}$, assumed a $100 \%$ outlier probability for Burial 111, but emphasized the stratigraphic intermediacy of Burial 103 between Burial 111 and the other 2 Early Classic determinations (as invariably verified by the 2006 model runs). Thus, Burial 103 was now an ordered parameter following Burial 111 in the earlier of 2 chronologically abutting determination groups.

Tabular results for the 3 models with TL dates extracted are presented in Table 4. Posterior results for the first 2 determinations are comparable in all 3 models. However, explicit recognition of Burial 111 's status as an outlier and stratigraphically inverted assay in $\mathrm{BCal}$ has a noticeable effect on the last 4 determinations, shifting the modal values of some determinations from cal AD 500 to 430 . Deciding which simulated results are correct obviously hinges on my prior archaeological belief that Burial 111 stratigraphically preceded Burial 103 and that the 2 AMS determinations are inverteda virtual certainty in my mind (see Model 3 below). Modal values for Burial 111 and Burial 103 in Model $1 \mathrm{~b}$ accord best with archaeological observations. The answer is less clear for the Stela 1 wood and Burial 106 bone. Modal values for these 2 materials cluster at cal AD 420/430 in Model 1a and at cal AD 490/500 in Model 1b. Their early placement in Model 1a results from the statistical "pull" of the Burial 103 assay. Archaeological data more abundantly support this earlier placement. Although the later cal AD 500 date cannot be conclusively discounted, results of my original 2006 analysis (see Models 4 and 5 below) suggest that all these events occurred about cal AD 430 .

Table 4 Posterior results of modeled acropolis sequence with TL determinations removed. Shaded modal values accord best with archaeological observations and correspond favorably to other sensitivity tests.

\begin{tabular}{lllllll}
\hline & \multicolumn{2}{c}{ OxCal v 4.0.1 } & \multicolumn{2}{c}{ Model 1a } & \multicolumn{2}{c}{ Model 1b } \\
\cline { 2 - 7 } Determination & 95\% HPD & Modal & 95\% HPD & Modal & 95\% HPD & Modal \\
\hline AA-66267 (B. 104) & AD 127-309 & AD 140 & AD 128-305 & AD 140 & AD 129-308 & AD 150 \\
AA-66268 (B. 102) & AD 143-322 & AD 200 & AD 142-326 & AD 225 & AD 145-328 & AD 210 \\
AA-66264 (B. 111) & AD 344-497 & AD 430 & AD 237-558 & AD 435 & AD 240-488 & AD 355 \\
AA-66263 (B. 103) & AD 396-556 & AD 500 & AD 331-545 & AD 420 & AD 325-542 & AD 420 \\
AA-67901 (St. 1 wood) & AD 421-557 & AD 500 & AD 410-546 & AD 440 & AD 410-552 & AD 490 \\
AA-66265 (B. 106) & AD 406-554 & AD 500 & AD 380-549 & AD 420 & AD 355-550 & AD 500 \\
\hline
\end{tabular}

Inclusion of the $2 \mathrm{TL}$ determinations significantly altered the shape of a key posterior parameter, the HPD region of Burial 103. Removal of these dates proved critical in deciding whether Burial 103, and thus the site's Early Classic destruction, occurred around cal AD 420-430 or around cal AD 500 (see Model 3 below).

\footnotetext{
${ }^{5}$ Overall model agreement is calculated using the pseudo-Bayes factor formula described in Bronk Ramsey (2005). This index gauges how consistent a model is with the age measurements used. Models that contain inverted determinations or determinations with large error terms (as is the case here with TL) will yield lower agreement indices than models that do not. In sum, this index measures the overall extent to which unsimulated determinations match simulated Bayesian results in any model.
} 


\section{Model 2: Dating the Hiatus Between the Early and Late Protoclassic}

Site formation and ceramic evidence suggest a brief hiatus in acropolis use and/or site occupation during the middle of the Protoclassic period (maximally 75 BC-AD 420). Mounds 6 and 7 contain buildings that incurred severe structural damage at the end of Early Protoclassic times. In addition, certain ceramic types in the Structure 6A-Sub 3 mask wall and Structure 7-Sub 3 platform, which are identical in building construction methods, are surely Late Protoclassic in date. Two ${ }^{14} \mathrm{C}$ dates bracket either side of the suspected hiatus. The dates are inverted, but their 2 standard deviations overlap. AA-66267 (B. 104) dates the death of the individual placed in Structure 6A-Sub 5 when the building was repaved in Early Protoclassic times. AA-66268 (B. 102) dates the death of the individual whose grave intruded into Structure 6A-Sub 4 (the aforementioned repavement), an event that possibly heralded construction of the Structure 6B stela enclosure. Thus, the 2 determinations are stratigraphically sequential and closely situated in time, but an episode of severe structural damage is spaced between them.

I created a Bayesian model that accounted for the stratigraphic priority of Burial 104 in relation to Burial 102 to better gauge the timing of these events and the duration of the surmised hiatus in monument use. The calibration model was run 3 times in OxCal and BCal with a statistical sampler of 50,000 iterations collected at intervals of 50. OxCal and $\mathrm{BCal}$ results were comparable. They implied that we can believe, a posteriori, that there is a 90\% chance that the occupant of Burial 104 died between AD 125 and 261 (Figure 9), an 87\% chance that the occupant of Burial 102 died between AD 134 and 259 (Figure 10), and a 95.4\% chance that the Protoclassic hiatus observed architecturally lasted between 1 and $100 \mathrm{yr}$ (Figure 11). Bayesian-derived probability curves peaked, however, around specific dates. Burial 104's curve peaked at AD 140, Burial 102's at AD 200, and the Protoclassic hiatus in the 10-20 yr interval. BCal probability analysis revealed a $75 \%$ chance that Burial 104 postdated AD 150.

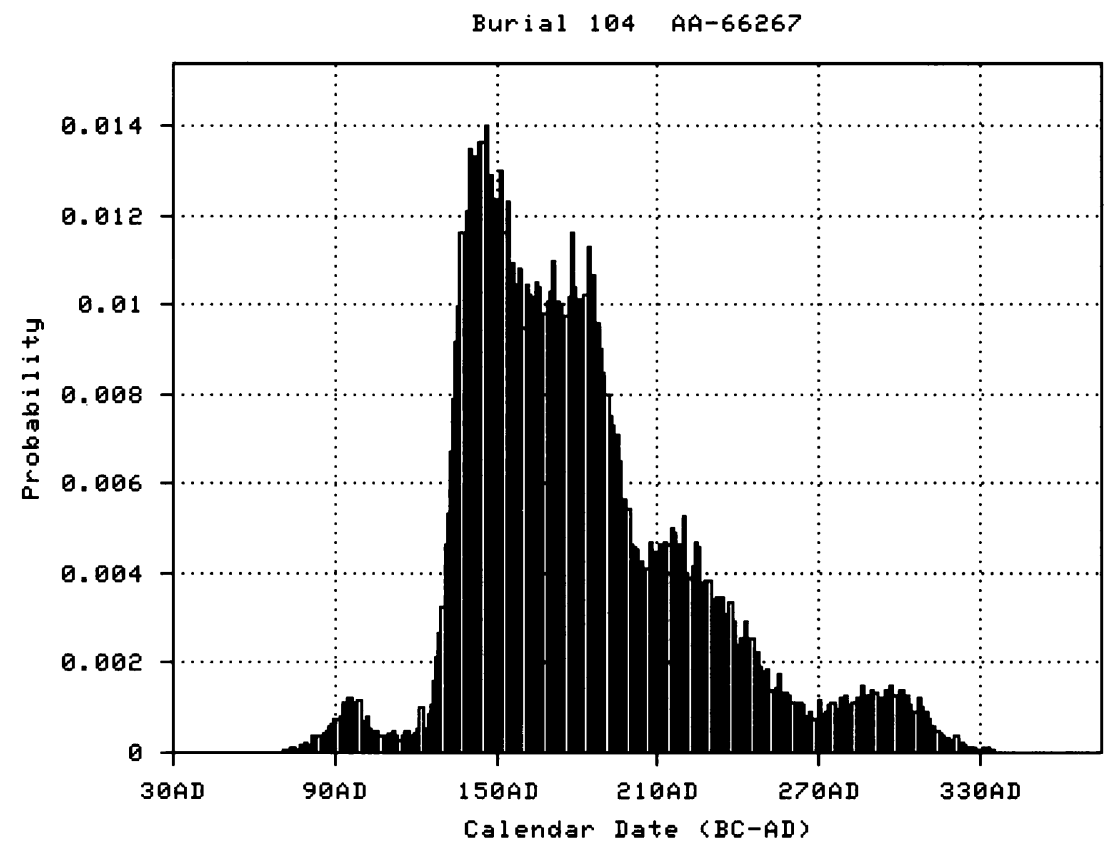

Figure 9 BCal posterior probability for $\theta_{1}$ (Burial 104, sample AA-66267) 


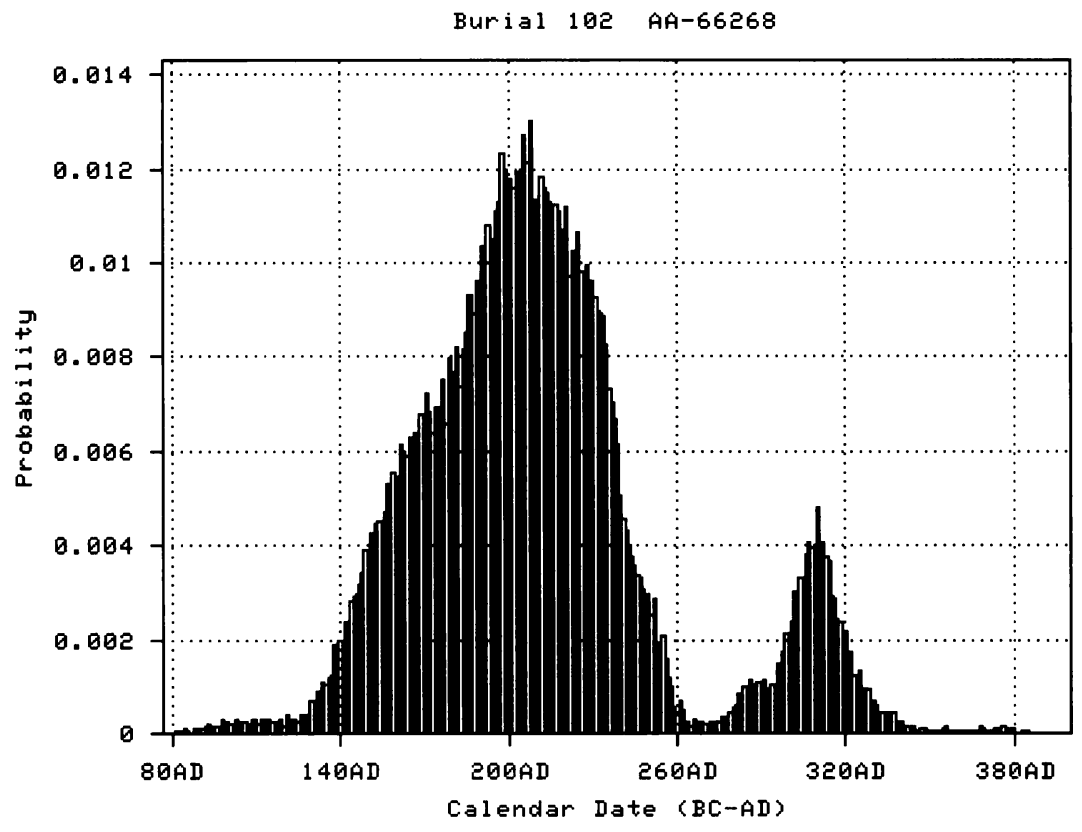

Figure $10 \mathrm{BCal}$ posterior probability for $\theta_{2}$ (Burial 102, sample AA-66268)

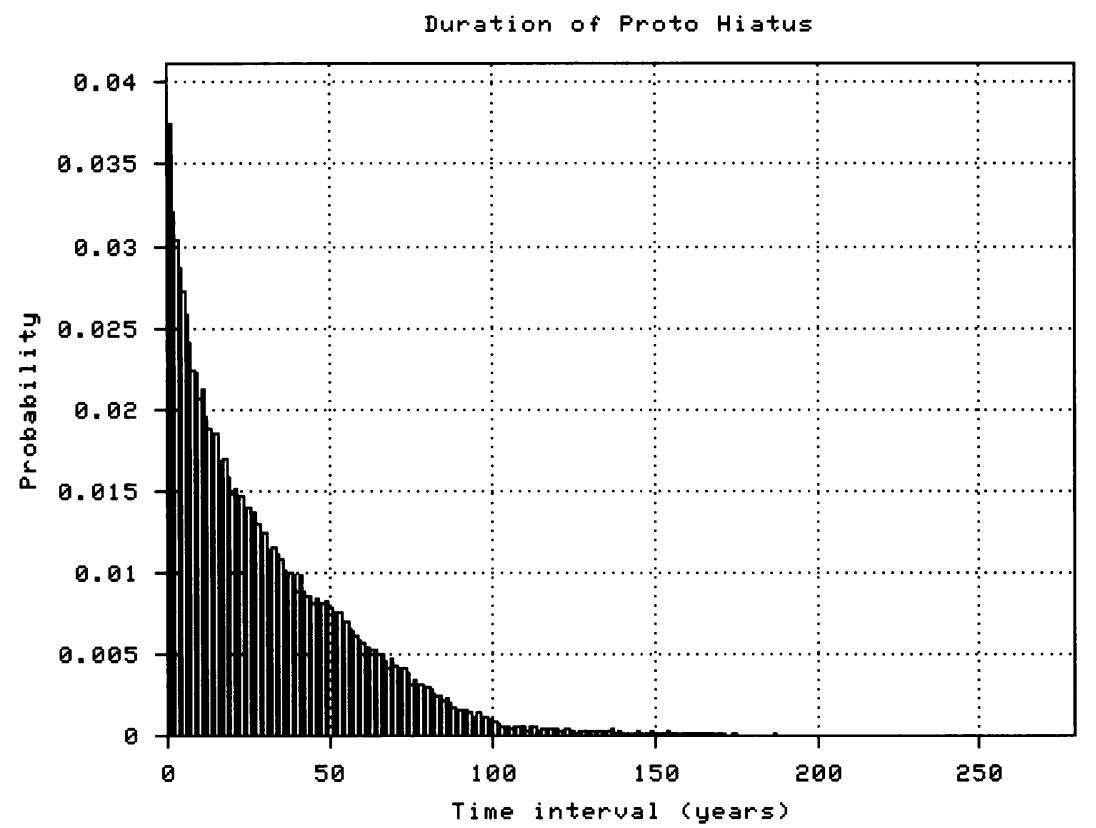

Figure $11 \mathrm{BCal}$ posterior probability for timespan separating $\theta_{1}$ and $\theta_{2}$

What this suggests is that Punta de Chimino's Protoclassic hiatus lasted 10-20 yr and occurred closer to $\mathrm{AD} 200$ than to $\mathrm{AD} 150$. This interpretation would be invalid of course if the ${ }^{14} \mathrm{C}$ dates are erroneous, if the intervals between dated events (deaths) and stratigraphic contexts are great, or if stratigraphic relationships have been misinterpreted. Given my current understanding of the archaeology, I have little reason to believe these offsetting factors are at play or of significant magnitude to impact results. 


\section{Model 3: Dating Burials 111 and 103 in Mound 7}

Stratigraphic and ceramic findings unequivocally demonstrate that Burial 111 predates the adjacent Burial 103, an intrusive circular-cist burial containing the remains of a migrant raised in the central or west-central lowlands (Wright and Bachand 2008). Burial 111's calibrated assay (AA-66264) is mainly too late for its context, especially if we consider the strong architectural ties between Structure 7-Sub 3 and Structure 6A-Sub 3, the latter being built sometime between AD 200 and 400. Accordingly, an outlier probability of $100 \%$ should be assigned to Burial 111's determination. The 2 AMS readings on skeletal long bone overlap significantly, and suggest that Burial 111's occupant died about the same time or even after Burial 103's. This latter case is a stratigraphic impossibility, however, and so the 2 dates must be inverted. Nevertheless, the 2 inhumations probably had some shared relationship, as suggested by their spatial and temporal proximity. A short generational gap between the deaths is highly likely. Thus, the creators of Burial 103 conceivably knew where Burial 111 was located.

To better gauge the timing and temporal distance between the 2 deaths, I generated a Bayesian model that accounted for Burial 111's stratigraphic priority. I ran the model 3 times in OxCal and $\mathrm{BCal}$, setting the sampling modulators at 50,000 iterations. In $\mathrm{BCal}$, a $100 \%$ outlier probability was assigned to AA- 66264 because only the very early end of the assay conformed to stratigraphic and ceramic observations. $\mathrm{BCal}$ and $\mathrm{OxCal}$ results differed significantly because $\mathrm{OxCal}$ did not provide a means to specify prior outlier probability. In this case, $\mathrm{BCal}$ results are considered more accurate. Readers should be aware that a prior outlier probability of $50 \%$ for Burial 111 made the results 10 20 yr later.

As for the duration between mortality events, OxCal provides a $95.4 \%$ posterior probability that it was somewhere between 1 and $100 \mathrm{yr}$. However, the BCal graph (Figure 12) illustrates that a shorter interval of less than $50 \mathrm{yr}$ is far more likely-a result conditioned by the prior outlier probability stated in BCal.

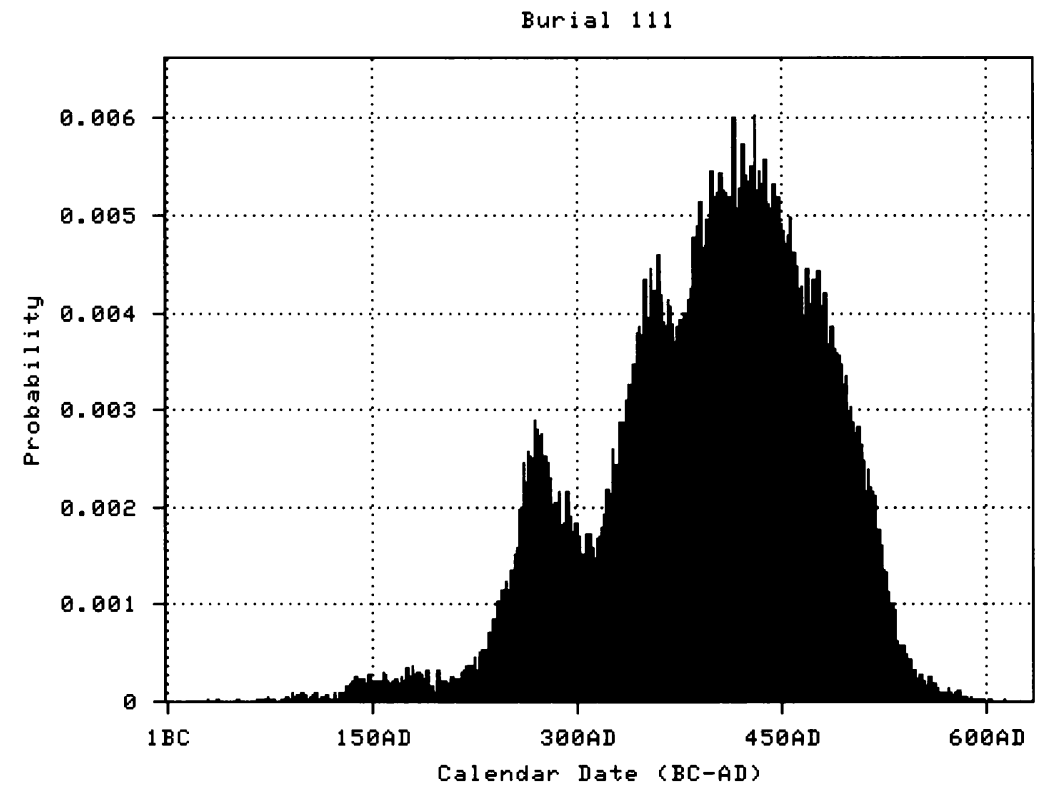

Figure $12 \mathrm{BCal}$ posterior probability for $\theta_{3}$ (Burial 111, sample AA-66264) 
The true date of Burial 103 is of critical importance in understanding Punta de Chimino's Early Classic demise. BCal queries of Model 3 provide a $69 \%$ posterior probability that Burial 103 postdates AD 430 (the destruction date postulated for Stela 1), and a $65 \%$ probability that it predates AD 500. In this simple 2-determination model, Burial 103's HPD plot is skewed to the right and nearly bimodal, peaking at AD 420 and again at AD 490-530 (Figure 13).

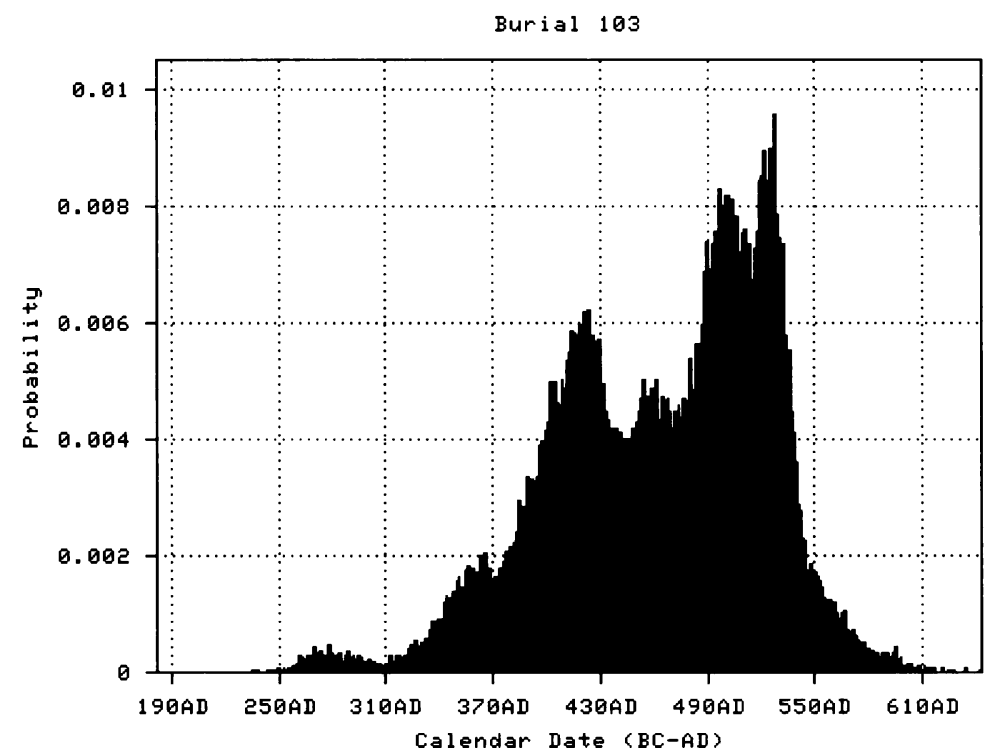

Figure $13 \mathrm{BCal}$ posterior probability for $\theta_{5}$ (Burial 103, sample AA-66263) when simulated with $\theta_{3}$ (Burial 111, sample AA-66264) in Model 3. The range and modal value of this histogram appear to be too late, given archaeological observations and the results of other models.

Which date range likely contains the true date of Burial 103? Numerous factors suggest that the person interred in Burial 103 died some time between cal AD 420 and 450. For one, the median calibrated age of AA-66263 before Bayesian analysis (AD 400) encourages earlier placement. Secondly, archaeological evidence suggests that Burial 111 dates no later than AD 400 (no Tzakol 2 artifacts were found in the grave or in the surrounding fill). As mentioned above, Bayesian queries imply that the gap between Burial 111 and Burial 103 is probably $50 \mathrm{yr}$ or less. Finally, and perhaps most significantly, Burial 103's HPD region changes when the assay is modeled in BCal with the other $6{ }^{14} \mathrm{C}$ determinations in the acropolis sequence. The histogram skews to the left and peaks between cal AD 400 and 420 (Figure 14). It becomes almost unimodal when Burial 103 is ordered a priori as the first Early Classic event-an assumption that all models invariably demonstrate (Figure 15).

\section{Model 4: Dating Stela 1 and Early Classic Site Abandonment}

One of the more significant events at Punta de Chimino in the Late Protoclassic was the erection of Stela 1. We do not know what was portrayed on the monument, but its purposes and meanings were certainly linked to the turbulent events that triggered its removal. Numerous archaeological events revolve around Stela 1. Dates of interest are 1) the stela's erection date; 2) the construction date of its masonry enclosure, Structure 6B;3) the timing of structural enhancements made to Structure 6B; 


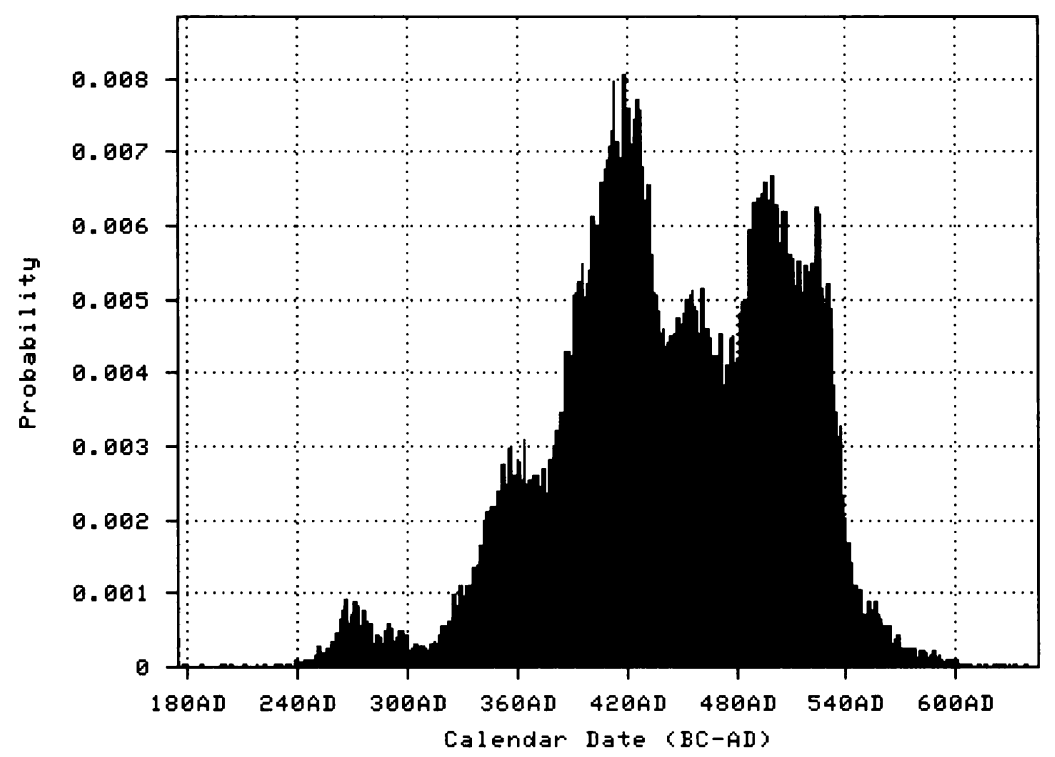

Figure $14 \mathrm{BCal}$ posterior probability for $\theta_{5}$ (Burial 103, sample AA-66263) when simulated in Model la as an unordered Early Classic event among the acropolis ${ }^{14} \mathrm{C}$ determinations. The modal value shifts to the left, peaking between AD 400 and 420 .

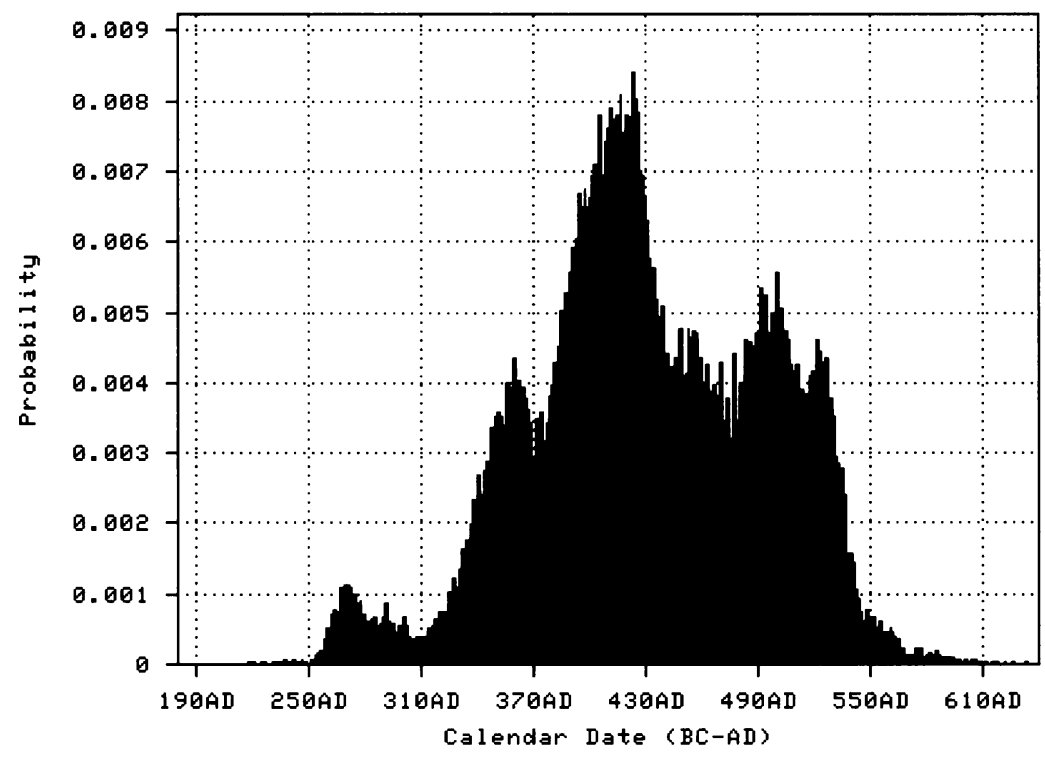

Figure $15 \mathrm{BCal}$ posterior probability for $\theta_{5}$ (Burial 103, sample AA-66263) when simulated in Model $\mathrm{lb}$ as the first Early Classic event among the acropolis ${ }^{14} \mathrm{C}$ determinations. The histogram becomes more unimodal and the modal value peaks between AD 400 and 420 .

4) the date of the simultaneous destruction of Stela 1 and Structure 6B in a probable fire ritual; 5) termination of the adjacent mask wall behind Structure 6B; and 6) the death (and burial) of the migrant across the plaza in Burial 103 (see Model 5 below). 
Regrettably, we have no direct radiometric date for Stela 1's erection. But if we surmise that Stela 1 was erected around the time its enclosure (Structure 6B) was built, we can use Burial 102 (AA66268 ) as a terminus post quem for Stela 1 erection. Stratigraphically, half of Burial 102 is covered by Structure 6B's south wall. The latest potsherds in the stela pit and in Structure 6B's fill matrix are Late Protoclassic in date. The late half of Burial 102's AMS result overlaps with the early half of the Late Protoclassic. Thus, equating Burial 102 with the early end of Stela 1's existence seems amply justified (Figure 16).

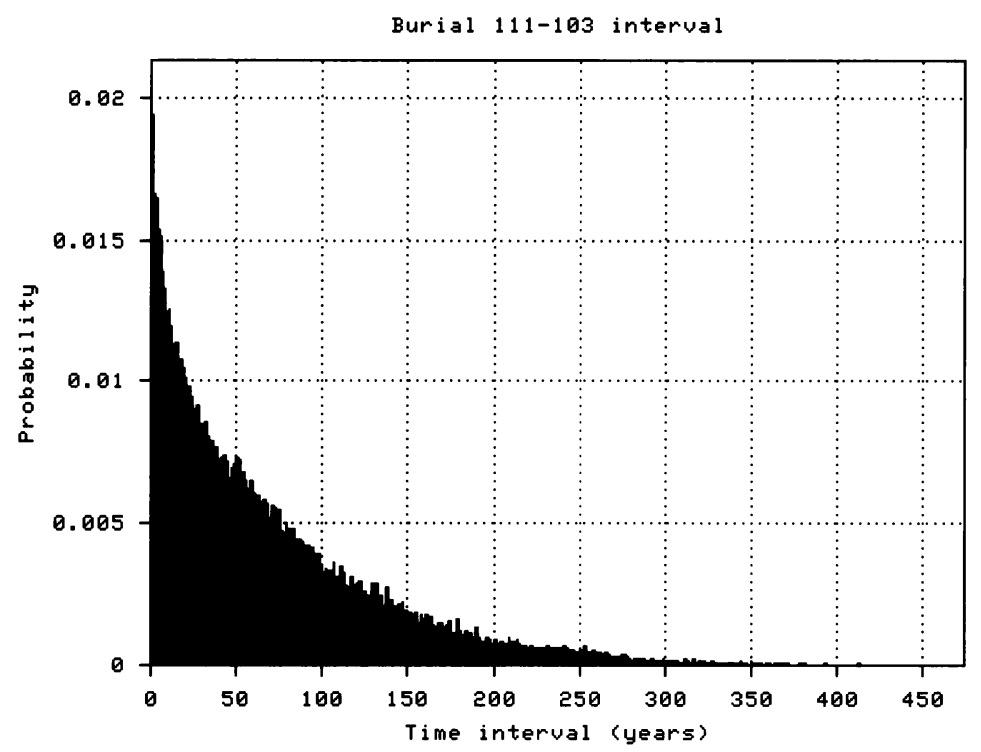

Figure $16 \mathrm{BCal}$ posterior probability for timespan separating $\theta_{3}$ and $\theta_{5}$

At least 1, and possibly 2, AMS determinations provide a direct date on Stela 1's destruction. The charred resinous wood (AA-67901) abutting the monument's south side was probably associated with a fire ritual that attended the monument's removal. The young juvenile (AA-66265) placed in the mask wall termination deposit where it spills onto the rear ledge of Structure 6B may be a casualty of the same destruction event. The deceased's calibrated AMS result is virtually the same as that of AA-67901, even though ceramic evidence suggests the mask wall may have been defaced a short while after Stela 1 was toppled. Stratigraphically, a more direct terminus ante quem for Stela 1 and Structure 6B is to be had in sample AA-67901.

Several structural modifications to Structure $6 \mathrm{~B}$ occurred between the termination events mentioned above. These include the addition of interior wing walls, creation of a sloping rear masonry wall, and removal of rear ledge stones to create a "bench" in front of mask 1 . Stratigraphically and ceramically, Stela 1 appears to have originated in Late Protoclassic times prior to the appearance of Burial 103.

A simple Bayesian model was designed to isolate the time interval when Stela 1 and Structure 6B existed and to estimate the stela's longevity. Because some doubt remained as to the contemporaneity of Stela 1's ritual destruction and infilling of the adjacent mask wall corridor, sample AA-66265 was removed from the simulation. Not surprisingly, combining and averaging AA-67901 and AA66265 into a single terminus ante quem had an impact on Bayesian results, kicking Stela 1's destruc- 
tion out into the late 5th century and establishing a 250- to 300-yr use-life for the monument. ${ }^{6}$ Recalling that AA-66268 was an inverted assay, 3 relevant determinations (AA-66267, AA-66268, and AA-67901) were simulated several times in OxCal and BCal with the iteration number set at 50,000 .

Results showed that the resinous wood posterior probability curve peaked around AD 430 (Figure 17). Statistically and archaeologically, this was an attractive date for the burning event associated with ritual destruction of Stela 1. An interval of $230 \mathrm{yr}$ was calculated between Stela 1's probable erection (Burial 102 terminus post quem $\sim \mathrm{AD} 200$ ) and destruction around $\mathrm{AD} 430$. This duration was just $20 \mathrm{yr}$ shy of the extrapolated 250-yr HPD modal value for the monument's existence (Figure 18). This implied that Stela 1 stood for more than 2 centuries before it was decommissioned, a conclusion exceeding expectations.

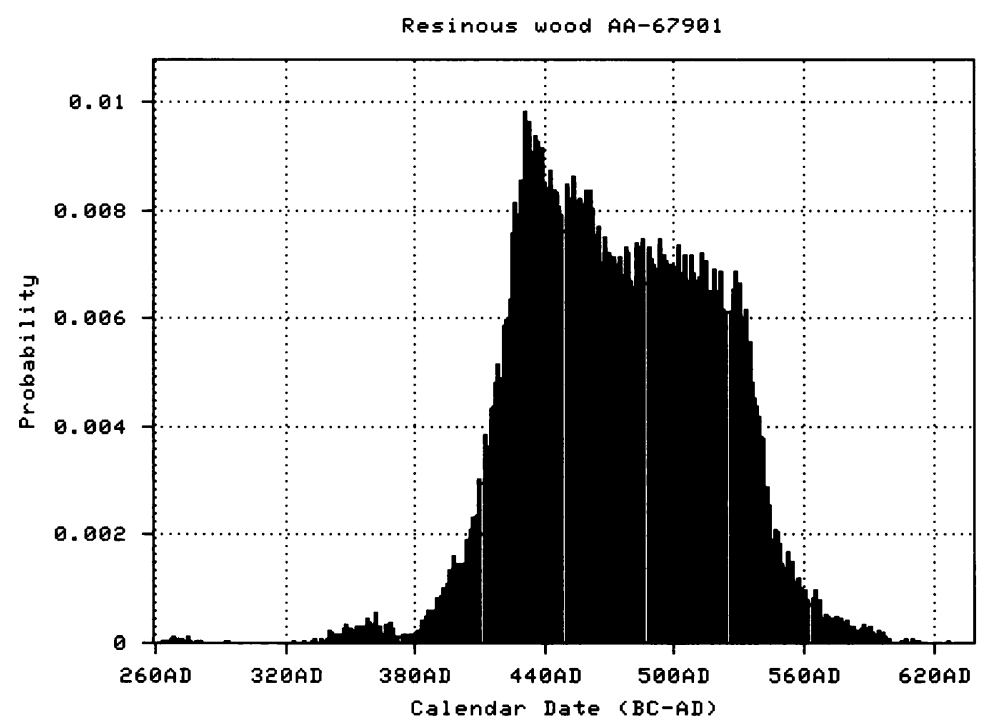

Figure 17 BCal posterior probability for $\theta_{6}$ (resinous wood, sample AA-67901)

It must be remembered that the foregoing estimates of stela erection and longevity are conservative maximum age estimates. I do not know exactly when Stela 1 was erected; I only believe the stela enclosure appeared with or after Burial 102 (whether the inhumation was primary or secondary). The $6 \mathrm{~B}$ building could have lacked a stela for many years. Alternatively, the stela may have preceded the building. Existing data do not permit recognition of any temporal lag between Stela 1 erection and Structure 6B construction. In conclusion, Bayesian analyses allow us to surmise with confidence that Stela 1 existed maximally between AD 200 and 450, with an option that the monolith appeared during the latter half of this period if Burial 102 is secondary.

\section{Model 5: Chronological Relationship Between Stela 1 Destruction and Burial 103}

A major question of interest was whether Burial 103's migrant occupant died before, after, or at the time of Stela 1's destruction. This was tested in BCal with a simple Bayesian model that assumed no temporal ordering between the $2{ }^{14} \mathrm{C}$ events. The results were surprising. The graph in Figure 19 was

${ }^{6}$ Averaging ${ }^{14} \mathrm{C}$ determinations is generally an unsound scientific practice (see Bowman 1990:60-2). 


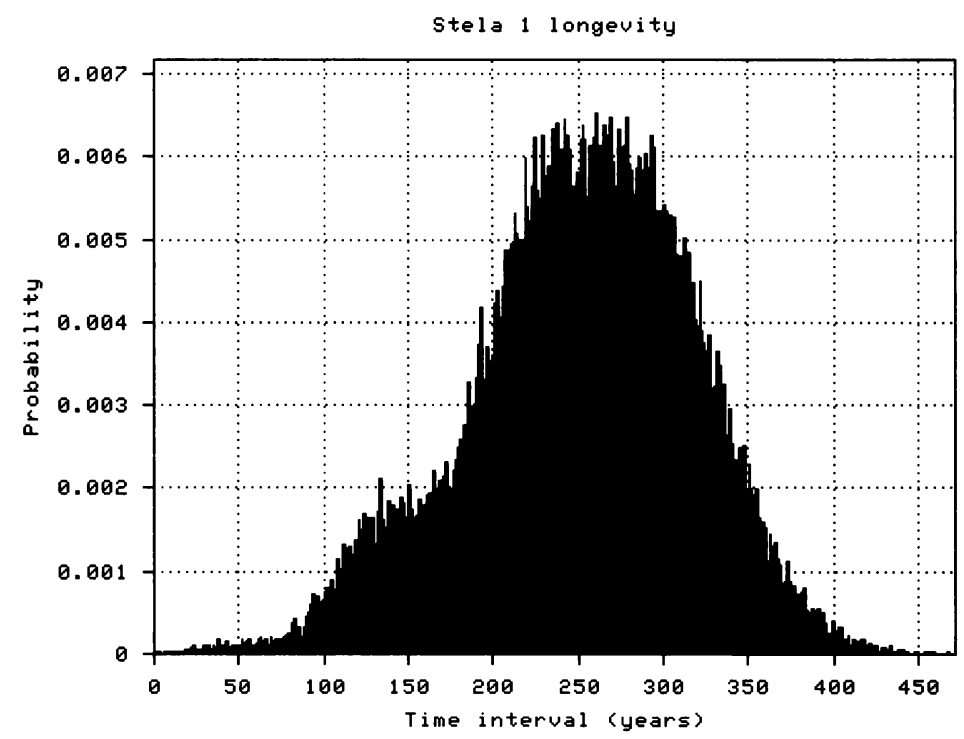

Figure $18 \mathrm{BCal}$ posterior probability for the timespan between $\theta_{2}$ and $\theta_{6}$. Timespan is maximum time allotted for existence of Stela 1.

generated in response to the query, "What is the time interval between Burial 103 and Stela 1 destruction?" The probability peaked at zero. I then posed 2 questions to the model: 1) what is the probability that Burial 103 is earlier than Stela 1's destruction? and 2) what is the probability that Burial 103 is later than Stela 1 destruction? The result was a 69\% probability that Burial 103's occupant died before the resinous wood used in the Stela 1 termination and a $30 \%$ chance that the individual's death occurred thereafter. In BCal, we are given quantification of the greater probability that Burial 103 predates Stela 1's destruction, as consistently determined in Model 1, the OxCal simulation. These results imply a close historical connection between the 2 events.

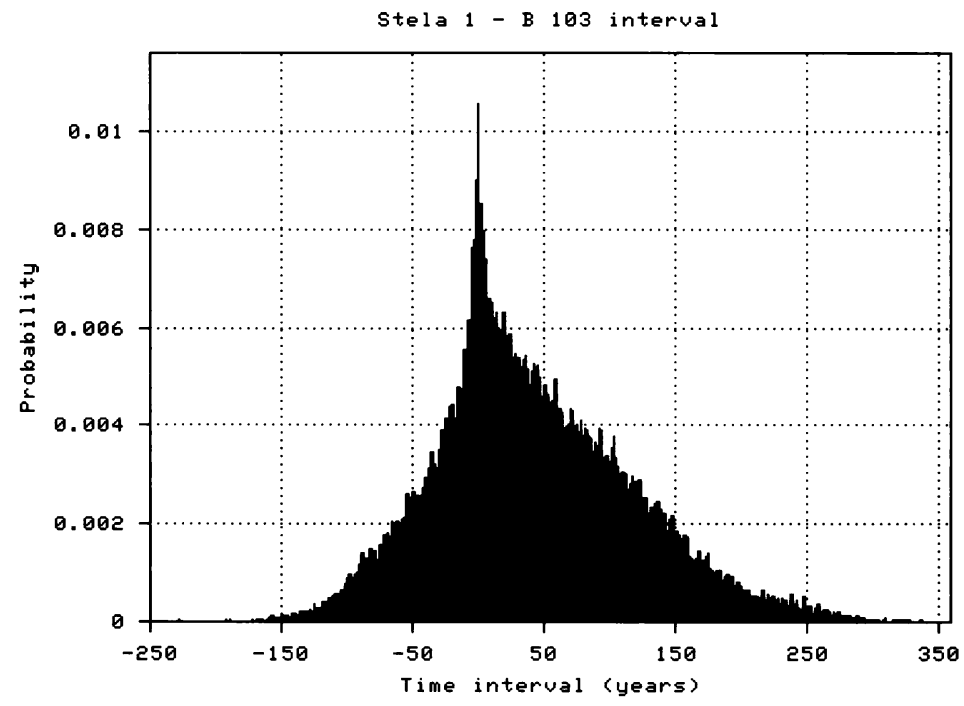

Figure $19 \mathrm{BCal}$ posterior probability for elapsed time between $\theta_{6}$ (Stela l's destruction) and $\theta_{4}$ (Burial 103 mortality). 


\section{CONCLUSION}

The above models suggest that Punta de Chimino's monumental center was neglected for several decades at the end of the 2nd century AD, rebuilt around cal AD 200, and ritually destroyed around cal AD 430/450. This last date is especially important because it associates Punta de Chimino's destruction with the Mexican-inspired Tikal expansion between AD 378-508 (Martin 2003), rather than with the rise of the first dynastic polity at neighboring Tamarindito at AD 513 (Mathews and Willey 1991:43). Modal values, sensitivity tests, and numerous archaeological findings (Bachand 2006) provide greater support for the earlier placement (see Table 3).

Modal values have received little attention in Bayesian radiometry (but see Anderson et al. 2001). When modal values from a number of carefully selected, stratigraphically contemporaneous determinations repeatedly gravitate toward a particular calendar range in a variety of differently configured models, as was the case at Punta de Chimino, the true calendar date for an event would appear to lie within that range.

Bayesian-adjusted determinations fall short of being absolute, but they can bring us closer to the mark, thereby enhancing our efforts to unravel the past. For Mesoamerican sites like Punta de Chimino that lack dated monuments, a reduction of centuries into decades transforms epochs into generational moments, placing archaeological time onto the historical stage.

\section{ACKNOWLEDGMENTS}

Research at Punta de Chimino was authorized by the Guatemalan Instituto de Antropología e Historia with permits granted to Takeshi Inomata and Daniela Triadan, directors of the Aguateca Archaeological Project. ${ }^{14} \mathrm{C}$ and luminescence dating was funded by National Science Foundation Grant No. BCS-0404027 and by Brigham Young University's New World Archaeological Foundation. I am indebted to Timothy Jull, Greg Hodgins, and Mitzi DeMartino of the NSF Arizona AMS Facility for providing assistance at various stages of the ${ }^{14} \mathrm{C}$ processing. Lee Newsom of Pennsylvania State University kindly agreed to identify the paleobotanical samples prior to their pretreatment. James Feathers, director of the Luminescence Dating Laboratory at the University of Washington, was helpful, candid, and supportive in his advisement and reporting of what was, in my experience, a potentially useful but more complicated procedure than ${ }^{14} \mathrm{C}$ dating. Bayesian radiometry would be difficult to undertake were it not for the OxCal computer platform created at Oxford University by Christopher Bronk Ramsey and the BCal program engineered by Caitlin Buck and associates at the University of Sheffield. I am indebted to David Killick, Tom Dye, and Jeffrey Dean for helping me understand the pitfalls and untapped potential of radiometric dating in archaeology. Andrés Christen and Christopher Bronk Ramsey clarified the meaning of modes in Bayesian graphs. Ian Robertson provided a detailed, incisive review of this paper, greatly enhancing its clarity. I, of course, absorb all liability for errors of content or interpretation.

\section{REFERENCES}

Anderson A, Higham T, Wallace R. 2001. The radiocarbon chronology of the Norfolk Island archaeological sites. In: Anderson A, White P, editors. The Prehistoric Archaeology of Norfolk Island, Southwest Pacific. Sydney: Australian Museum. p 33-42.

Bachand BR. 2006. Preclassic excavations at Punta de Chimino, Petén, Guatemala: investigating social emplacement on an Early Maya landscape [PhD dissertation]. Tucson: University of Arizona.
Bayliss A, Bronk Ramsey C, McCormac FG. 1997. Dating Stonehenge. In: Cunliffe B, Renfrew C, editors. "Science and Stonehenge." Proceedings of the British Academy 92:39-59.

Bayliss A, McAvoy F, Whittle A. 2006. The world recreated: redating Silbury Hill in its monumental landscape. Antiquity 81(311):26-53.

Bayliss A, Bronk Ramsey C, van der Plicht J, Whittle A. 2007a. Bradshaw and Bayes: towards a timetable for 
the Neolithic. Cambridge Archaeological Journal 17(Supplement S1):1-28.

Bayliss A, Whittle A, Wysocki M. 2007b. Talking about my generation: the date of the West Kennet Long Barrow. Cambridge Archaeological Journal 17(Supplement S1):85-101.

Bowman S. 1990. Radiocarbon Dating. Berkeley: University of California Press. 64 p.

Brady JE, Ball JW, Bishop RL, Pring DC, Hammond N, Housley RA. 1998. The Lowland Maya "Protoclassic": a reconsideration of its nature and significance. Ancient Mesoamerica 9(1):17-38.

Bronk Ramsey C. 1995. Radiocarbon calibration and analysis of stratigraphy: the OxCal program. Radiocarbon 37(2):425-30.

Bronk Ramsey C. 1998. Probability and dating. Radiocarbon 40(1):461-74.

Bronk Ramsey C. 2000. Comment on "The use of Bayesian statistics for ${ }^{14} \mathrm{C}$ dates of chronologically ordered samples: a critical analysis." Radiocarbon 42(2):199202.

Bronk Ramsey C. 2005. OxCal program v 3.10 manual. http://www.rlaha.ox.ac.uk/oxcal/arch_str.htm\#warn. Accessed 9 February 2008.

Buck CE, Blackwell PG. 2004. Formal statistical models for estimating radiocarbon calibration curves. Radiocarbon 46(3): 1093-102.

Buck CE, Kenworthy JB, Litton CD, Smith AFM. 1991. Combining archaeological and radiocarbon information: a Bayesian approach to calibration. Antiquity 65(249):808-21.

Buck CE, Litton CD, Smith AFM. 1992. Calibration of radiocarbon results pertaining to related archaeological events. Journal of Archaeological Science 19(5): 497-512.

Buck CE, Litton CD, Shennan SJ. 1994. A case study in combining radiocarbon and archaeological information: the Early Bronze Age settlement of St. VeitKlinglberg, Land Salzburg, Austria. Germania 72(2): 427-47.

Buck CE, Cavanagh WG, Litton CD. 1996. Bayesian Approach to Interpreting Archaeological Data. Barnett V, editor. New York: John Wiley \& Sons. 402 p.

Dean JS. 1978. Independent dating in archaeological analysis. In: Schiffer MB, editor. Advances in Archaeological Method and Theory. Volume 1. New York: Academic Press. p 223-55.

Demarest AA. 2006. The Petexbatún Regional Archaeological Project: A Multidisciplinary Study of the Maya Collapse. Demarest AA, editor. Nashville: Vanderbilt University Press. $256 \mathrm{p}$.

Dunning NP, Beach T, Rue DJ. 1997. The paleoecology and ancient settlement of the Petexbatún region, Guatemala. Ancient Mesoamerica 8(2):185-97.

Foias AE. 1996. Changing ceramic production and exchange systems and the Classic Maya collapse in the
Petexbatún region [PhD dissertation]. Nashville: Vanderbilt University.

Howson C, Urbach P. 2006. Scientific Reasoning: The Bayesian Approach. Chicago: Open Court Publishing Company. $492 \mathrm{p}$.

Lu X, Guo Z, Ma H, Yuan S, Wu X. 2001. Data analysis and calibration of radiocarbon dating results from the cemetery of the Marquises of Jin. Radiocarbon 43(1): 55-62.

Marcus J. 2003. Recent advances in Maya archaeology. Journal of Archaeological Research 11(2):71-148.

Martin S. 2003. In line of the founder: a view of dynastic politics at Tikal. In: Sabloff JA, editor. Tikal: Dynasties, Foreigners, and Affairs of State. Santa Fe: School of American Research Press. p 3-45.

Mathews P, Willey GR. 1991. Prehistoric polities of the Pasión region: hieroglyphic texts and their archaeological settings. In: Culbert TP, editor. Classic Maya Political History: Hieroglyphic and Archaeological Evidence. Cambridge: Cambridge University Press. p 30-71.

Reimer PJ, Baillie MGL, Bard E, Bayliss A, Beck JW, Bertrand CJH, Blackwell PG, Buck CE, Burr GS, Cutler KB, Damon PE, Edwards RL, Fairbanks RG, Friedrich M, Guilderson TP, Hogg AG, Hughen KA, Kromer B, McCormac G, Manning S, Bronk Ramsey C, Reimer RW, Remmele S, Southon JR, Stuiver M, Talamo S, Taylor FW, van der Plicht J, Weyhenmeyer CE. 2004. IntCal04 terrestrial radiocarbon age calibration, 0-26 cal kyr BP. Radiocarbon 46(3):1029-58.

Sabloff JA. 1975. Ceramics. In: GR Willey, editor. Excavations at Seibal, Department of Peten, Guatemala. Cambridge: Harvard University. p i-261.

Shott MJ. 1992. Radiocarbon dating as a probabilistic technique: the Childers site and Late Woodland occupation in the Ohio Valley. American Antiquity 57(2): 202-30.

Smith RE, Gifford JC. 1966. Maya Ceramic Varieties, Types, and Wares at Uaxactún: Supplement to "Ceramic Sequence at Uaxactún, Guatemala." New Orleans: Tulane University. $49 \mathrm{p}$.

Steier P, Rom W. 2000. The use of Bayesian statistics for ${ }^{14} \mathrm{C}$ dates of chronologically ordered samples: a critical analysis. Radiocarbon 42(2): 183-98.

Whittle A, Bayliss A. 2007. The times of their lives: from chronological precision to kinds of history and change. Cambridge Archaeological Journal 17(1): 21-8.

Wright LE, Bachand BR. 2008. Strontium isotope identification of an Early Classic migrant to Punta de Chimino, Guatemala. Maya Archaeology (in press).

Zeidler JA, Buck CE, Litton CD. 1998. Integration of archaeological phase information and radiocarbon results from the Jama River Valley, Ecuador: a Bayesian approach. Latin American Antiquity 9(2):160-79. 


\section{APPENDIX}

Model 1: Protoclassic to Early Classic Acropolis Event Sequence

OxCal Model Definition

Plot

\{ Sequence "Proto-EC Acropolis Sequence"

\{

Boundary "start";

R_Date "AA-66267" 1756 41;

R_Date "AA-66268" 1871 43;

R_Date "AA-66264" 1568 45;

L_Date "UW-1152" 2186 520, dosage rate $=8.21$;

Order "Early Classic events"

\{

R_Date "AA-66263" 1634 53;

R_Date "AA-67901" 1582 37;

L_Date "UW-1154" 2050 410, dosage rate = 4.25;

R_Date "AA-66265" 1613 45;

\};

Boundary "end";

\};

\};

\section{OxCal Calibration Parameters}

Calibration curve: $\underline{\text { IntCal04 }}$

Cubic interpolation: yes

Uniform span prior: yes

MCMC iterations: $\underline{\mathbf{5 0 , 0 0 0}}$

Ranges: 2 sigma, 95.4\%

Probability method: yes

Round off ranges: yes, by: 1 yr

Resolution: $\underline{5}$

OxCal Results

AA-66267 (Burial 104): AD 133 (95.4\%) AD 323

AA-66268 (Burial 102): AD 151 (51.3\%) AD 261, AD 278 (44\%) AD 344

AA-66264 (Burial 111): AD 260 (5.4\%) AD 280, AD 325 (90\%) AD 473

UW-1152 (Unnamed Orange Poly): AD 328 (95.4\%) AD 504

Early Classic Order: AA-66263, AA-66265, AA-67901, UW-1154

AA-66263 (Burial 103): AD 378 (95.4\%) AD 550

AA-67901 (Resinous wood): AD 412 (95.4\%) AD 551

UW-1154 (Dos Arroyos Orange Poly): AD 351 (95.4\%) AD 634

AA-66265 (Burial 106): AD 392 (95.4\%) AD 546

Iterations used: 56,$995 ; 114,295 ; 28,496$ 
Model 1a: Protoclassic to Early Classic Acropolis Event Sequence (without TL Dates)

BCal Model Definition

Number of groups: $\underline{2}$

Number of floating parameters: $\underline{0}$

Group 1: main Proto-EC sequence

Number of determinations: $\underline{3}$

Determination parameter ordering: yes

Burial 104: $\underline{\text { AA- }} 662671756 \pm 41$ Outlier probability: $\underline{0}$

Burial 102: $\underline{\text { AA- }-662681871 \pm 43}$ Outlier probability: $\underline{0}$

Burial 111: $\underline{\text { AA- } 662641568 \pm 45}$ Outlier probability: 100

No pooled mean

Master calibration curve: Atmospheric 2004

No absolute chronological information for alpha 1 or beta 1 boundaries

Group relation: overlapping earlier

No absolute chronological information for Burial 104, Burial 102, or Burial 111

Determination parameter order: Burial 104 (1), Burial 102 (2), Burial 111 (3)

No floating parameters

Group 2: Early Classic events

Number of determinations: $\underline{3}$

Determination parameter ordering: $\underline{\text { no }}$

Burial 103: $\underline{\mathrm{AA}}-662631634 \pm 53$ Outlier probability: $\underline{0}$

Stela 1 wood: $\underline{\mathrm{AA}-679011582 \pm 37}$ Outlier probability: $\underline{0}$

Burial 106: AA-66265 1613 \pm 45 Outlier probability: $\underline{0}$

No pooled mean

Master calibration curve: Atmospheric 2004

No absolute chronological information for alpha 1 or beta 1 boundaries

Group relation: overlapping later

No absolute chronological information for Stela 1 wood or B. 106

Determination parameter order: none

No floating parameters

\section{BCal Calibration Parameters}

Precision for internal calculations: 10

Seed for pseudorandom number generator: -1

Bin width for histograms: 1

MCMC sampling long run size (burn In): 1000

MCMC sampling interval: $\underline{\mathbf{5 0}}$

Minimum sample size: $\underline{50,000 \text { iterations }}$

Convergence checking sensitivity level: $\underline{5 \text { (very strict) }}$

BCal Results

Burial 104: AD 128 to AD 261, AD 281 to AD 305

Burial 102: AD 142 to AD 257, AD 292 to AD 326

Burial 111: AD 237 to AD 558 
Burial 103: AD 331 to AD 545

Stela 1 wood: AD 410 to AD 546

Burial 106: AD 380 to AD 549

Iterations used: $\underline{50,000}$

Model 1b: Protoclassic to Early Classic Acropolis Event Sequence (without TL Dates)

BCal Model Definition

Number of groups: $\underline{2}$

Number of floating parameters: $\underline{0}$

Group 1: main Proto-EC sequence

Number of determinations: $\underline{4}$

Determination parameter ordering: yes

Burial 104: $\underline{\text { AA- } 662671756 \pm 41}$ Outlier probability: $\underline{0}$

Burial 102: $\underline{\text { AA-66268 } 1871 \pm 43}$ Outlier probability: $\underline{0}$

Burial 111: $\underline{\text { AA-66264 1568 } \pm 45}$ Outlier probability: 100

Burial 103: $\underline{\text { AA-66263 } 1634 \pm 53}$ Outlier probability: $\underline{0}$

No pooled mean

Master calibration curve: Atmospheric 2004

No absolute chronological information for alpha 1 or beta 1 boundaries

Group relation: overlapping earlier

No absolute chronological information for B. 104, B. 102, B. 111, or B. 103

Determination parameter order: B. 104 (1), B. 102 (2), B. 111 (3), B. 103 (4)

No floating parameters

Group 2: Stela 1 destruction

Number of determinations: $\underline{2}$

Determination parameter ordering: $\underline{\text { no }}$

Stela 1 wood: $\underline{\text { AA- }} 679011582 \pm 37$ Outlier probability: $\underline{0}$

Burial 106: $\underline{\text { AA- } 662651613 \pm 45}$ Outlier probability: $\underline{0}$

No pooled mean

Master calibration curve: Atmospheric 2004

No absolute chronological information for alpha 1 or beta 1 boundaries

Group relation: overlapping later

No absolute chronological information for Stela 1 wood or B. 106

Determination parameter order: none

No floating parameters

\section{BCal Calibration Parameters}

Precision for internal calculations: $\underline{10}$

Seed for pseudorandom number generator: -1

Bin width for histograms: 1

MCMC sampling long run size (burn In): 1000

MCMC sampling interval: $\underline{50}$

Minimum sample size: $\underline{50,000 \text { iterations }}$

Convergence checking sensitivity level: $\underline{5 \text { (very strict) }}$ 
BCal Results

Burial 104: AD 129 to AD 262, AD 275 to AD 308

Burial 102: AD 145 to AD 257, AD 294 to AD 328

Burial 111: AD 240 to AD 488

Burial 103: AD 325 to AD 542

Stela 1 wood: AD 410 to AD 552

Burial 106: AD 355 to AD 368, AD 379 to AD 550

Iterations used: $\underline{50,000}$

Model 2: Dating the Hiatus Between Protoclassic 1 and 2

OxCal Model Definition

Plot

\{

Sequence

\{

Boundary;

Sequence "Burials $104 \& 102 "$

\{

R_Date "AA-66267" 1756 41;

Interval "Protoclassic hiatus";

R_Date "AA-66268" 1871 43;

\};

Boundary;

\};

\};

OxCal Calibration Parameters

Calibration curve: IntCal04

Cubic interpolation: yes

Uniform span prior: yes

MCMC iterations: $\underline{50,000}$

Ranges: 2 sigma, $95.4 \%$

Probability method: yes

Round off ranges: yes, by: 1 yr

Resolution: $\underline{\mathbf{5}}$

OxCal Results

AA-66267 (Burial 104): AD 125 (91\%) AD 261, AD 275 (4.4\%) AD 309

AA-66268 (Burial 102): AD 134 (88\%) AD 259, AD 292 (7.9\%) AD 324

Protoclassic hiatus duration: $-2(95.4 \%) 80 \mathrm{yr}$

Iterations used: $\underline{28,496}$

BCal Model Definition

Number of groups: 1

Number of floating parameters: $\underline{0}$

Number of determinations: $\underline{2}$ 
Determination parameter ordering: ordered

Burial 104: $\underline{\text { AA-}}-662671756 \pm 41$ Outlier probability: $\underline{0}$

Burial 102: $\underline{\mathrm{AA}-662681871 \pm 43}$ Outlier probability: $\underline{0}$

No pooled mean

Master calibration curve: Atmospheric 2004

No absolute chronological information for alpha 1 or beta 1 boundaries

No absolute chronological information for Burial 104 or Burial 102

Determination parameter order: Burial 104 (1), Burial 102 (2)

No floating parameters

\section{BCal Calibration Parameters}

Precision for internal calculations: $\underline{10}$

Seed for pseudorandom number generator: $\underline{-1}$

Bin width for histograms: 1

MCMC sampling long run size (burn In): 1000

MCMC sampling interval: $\underline{50}$

Minimum sample size: $\underline{50,000 \text { iterations }}$

Convergence checking sensitivity level: $\underline{5 \text { (very strict) }}$

BCal Results

Burial 104: AD 127 to AD 261, AD 283 to AD 295

Burial 102: AD 137 to AD 256, AD 295 to AD 323

Protoclassic hiatus duration: 1 to $93 \mathrm{yr}$

Iterations used: $\underline{50,000}$

\section{Model 3: Dating Burials 111 and 103 in Mound 7}

\section{OxCal Model Definition}

Plot

\{

Sequence

\{

Boundary;

Sequence "Burials 111 and 103"

\{

R_Date "AA-66264" 1568 45;

Interval "duration between burials";

R_Date "AA-66263" 1634 53;

\};

Boundary;

\};

\};

OxCal Calibration Parameters

Calibration curve: $\underline{\mathrm{IntCal04}}$

Cubic interpolation: yes

Uniform span prior: yes 
MCMC iterations: $\underline{50,000}$

Ranges: 2 sigma, $95.4 \%$

Probability method: yes

Round off ranges: yes, by: 1 yr

Resolution: $\underline{5}$

OxCal Results

AA-66264 (Burial 111): AD 385 (95.4\%) AD 540

AA-66263 (Burial 103): AD 405 (95.4\%) AD 565

Duration between burials: $-5(95.4 \%) 100 \mathrm{yr}$

Iterations used: $\underline{28,496}$

BCal Model Definition

Number of groups: 1

Number of floating parameters: $\underline{0}$

Number of determinations: $\underline{2}$

Determination parameter ordering: ordered

Burial 111: $\underline{\text { AA-66264 } 1568 \pm 45}$ Outlier probability: $\underline{100}$

Burial 103: $\underline{\text { AA- } 662631634 \pm 53}$ Outlier probability: $\underline{0}$

No pooled mean

Master calibration curve: Atmospheric 2004

No absolute chronological information for alpha 1 or beta 1 boundaries

No absolute chronological information for Burial 111 or Burial 103

Determination parameter order: Burial 111 (1), Burial 103 (2)

No floating parameters

BCal Calibration Parameters

Precision for internal calculations: $\underline{10}$

Seed for pseudorandom number generator: $\underline{-1}$

Bin width for histograms: 1

MCMC sampling long run size (burn In): 1000

MCMC sampling interval: $\underline{50}$

Minimum sample size: $\underline{50,000 \text { iterations }}$

Convergence checking sensitivity level: $\underline{5 \text { (very strict) }}$

BCal Results

Burial 111: AD 249 to AD 528

Burial 103: AD 344 to AD 557

Duration between burials: $200 \mathrm{yr}$

Iterations used: $\underline{\mathbf{5 0 , 0 0 0}}$

Model 4: Dating Stela 1 and Early Classic Site Abandonment

OxCal Model Definition

Plot

\{

Sequence 
\{

Boundary;

Sequence "Stela 1 sequence"

\{

R_Date "AA-6267" 1756 41;

R_Date "AA-6268" 1871 43;

R_Date "AA-67901" 1582 37;

\};

Boundary;

\};

\};

OxCal Calibration Parameters

Calibration curve: $\underline{\text { IntCal04 }}$

Cubic interpolation: yes

Uniform span prior: yes

MCMC iterations: $\underline{50,000}$

Ranges: 2 sigma, $95.4 \%$

Probability method: yes

Round off ranges: yes, by: 1 yr

Resolution: $\underline{5}$

OxCal Results

AA-66267 (Burial 104): AD 127 (95.4\%) AD 309

AA-66268 (Burial 102): AD 142 (75.8\%) AD 258, AD 282 (19.8\%) AD 333

AA-67901 (Resinous wood): AD 393 (95.4\%) AD 554

Iterations used: $\underline{28,496}$

BCal Model Definition

Number of groups: 1

Number of floating parameters: $\underline{0}$

Number of determinations: $\underline{3}$

Determination parameter ordering: ordered

Burial 104: $\underline{\mathrm{AA}-662671756 \pm 41}$ Outlier probability: $\underline{0}$

Burial 102: $\underline{\text { AA-}} 662681871 \pm 43$ Outlier probability: $\underline{0}$

Resinous wood: $\underline{\text { AA- }-679011582 \pm 37}$ Outlier probability: $\underline{0}$

Master calibration curve: Atmospheric 2004

No absolute chronological information for alpha 1 or beta 1 boundaries

No absolute chronological information for Burial 111 or Burial 103

Determination parameter order: Burial 104 (1), Burial 102 (2), Resinous wood (3)

No floating parameters

BCal Calibration Parameters

Precision for internal calculations: $\underline{10}$

Seed for pseudorandom number generator: $\underline{-1}$

Bin width for histograms: 1

MCMC sampling long run size (burn In): 1000 
MCMC sampling interval: $\underline{50}$

Minimum sample size: $\underline{50,000 \text { iterations }}$

Convergence checking sensitivity level: $\underline{5 \text { (very strict) }}$

BCal Results

Burial 104: AD 127 to AD 265, AD 276 to AD 303

Burial 102: AD 143 to AD 257, AD 291 to AD 328

Resinous wood: AD 402 to AD 550

Iterations used: $\underline{50,000}$

Model 5: Chronological Relationship Between Stela 1 Destruction and Burial 103

\section{BCal Model Definition}

Number of groups: 1

Number of floating parameters: $\underline{0}$

Number of determinations: $\underline{2}$

Determination parameter ordering: unordered

Burial 103: $\underline{\text { AA-66263 } 1634 \pm 53}$ Outlier probability: $\underline{0}$

Resinous wood: $\underline{\text { AA- }-679011582 \pm 37}$ Outlier probability: $\underline{0}$

Master calibration curve: Atmospheric 2004

No absolute chronological information for alpha 1 or beta 1 boundaries

No absolute chronological information for Burial 103 or Resinous wood

Determination parameter order: none

No floating parameters

\section{BCal Calibration Parameters}

Precision for internal calculations: $\underline{10}$

Seed for pseudorandom number generator: -1

Bin width for histograms: 1

MCMC sampling long run size (burn In): 1000

MCMC sampling interval: $\underline{50}$

Minimum sample size: $\underline{50,000 \text { iterations }}$

Convergence checking sensitivity level: $\underline{5 \text { (very strict) }}$

\section{BCal Results}

Burial 103: AD 263 to AD 277, AD 326 to AD 547

Resinous wood: AD 407 to AD 553

Iterations used: $\underline{\mathbf{5 0 , 0 0 0}}$ 